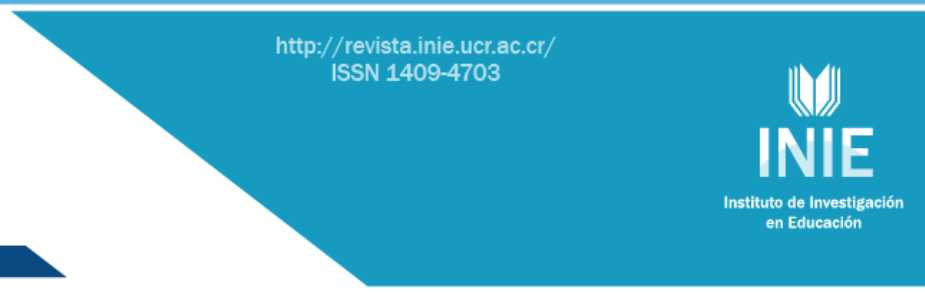

\title{
CONOCIMIENTOS TEÓRICOS Y ESTRATEGIAS METODOLÓGICAS QUE EMPLEAN DOCENTES DE PRIMER CICLO EN LA ESTIMULACIÓN DE LAS INTELIGENCIAS MÚLTIPLES
}

THEORETICAL CONCEPTUALIZATIONS AND METHODOLOGICAL STRATEGIES USED BY FIRST CYCLE TEACHERS IN IMPLEMENTING THE THEORY OF MULTIPLE INTELLIGENCES

\section{Volumen 15, Número 1}

Enero - Abril

pp. 1-39

Este número se publicó el $1^{\circ}$ de enero de 2015

DOI: dx.doi.org/10.15517/aie.v15i1.17727

Aida María Mainieri Hidalgo

Revista indizada en REDALYC, $\underline{\text { SCIELO }}$

Revista distribuida en las bases de datos:

CATÁLOGO DE LATINDEX, IRESIE, CLASE, DIALNET, DOAJ, E-REVIST@S, SHERPA/ROMEO, QUALIS, MIAR

Revista registrada en los directorios:

ULRICH'S, REDIE, RINACE, OEI, MAESTROTECA, PREAL, CLACSO 


\title{
CONOCIMIENTOS TEÓRICOS Y ESTRATEGIAS METODOLÓGICAS QUE EMPLEAN DOCENTES DE PRIMER CICLO EN LA ESTIMULACIÓN DE LAS INTELIGENCIAS MÚLTIPLES \\ THEORETICAL CONCEPTUALIZATIONS AND METHODOLOGICAL STRATEGIES USED BY FIRST CYCLE TEACHERS IN IMPLEMENTING THE THEORY OF MULTIPLE INTELLIGENCES
}

\begin{abstract}
Aida María Mainieri Hidalgo ${ }^{1}$
Resumen: Este artículo presenta los resultados de la investigación "Conocimientos teóricos y estrategias metodológicas que emplean docentes de primer ciclo en la estimulación de las inteligencias múltiples", desarrollada en la Maestría en Psicopedagogía de la Universidad Estatal a Distancia, Costa Rica. Se busca conocer las conceptualizaciones teóricas y las estrategias metodológicas que utiliza el profesorado de primer ciclo en la aplicación de la Teoría de las Inteligencias Múltiples (TIM) en el currículo. Se realizó con una metodología cualitativa y un enfoque interpretativo, se analizaron fuentes documentales y se aplicaron entrevistas en profundidad a docentes y expertos, utilizando un muestreo de tipo teórico, observación en el campo de trabajo y grupos focales en dos centros educativos privados, uno en San José, Costa Rica y otro en David-Panamá. Del análisis obtenido se extrae dos modelos de implementación para la estimulación de las inteligencias múltiples; los cuales sirven de referencia para indagar la puesta en práctica de esta teoría en tres escuelas públicas costarricenses. Como resultado se evidencian estrategias pedagógicas y evaluativas muy particulares que brindan una amplia perspectiva con respecto a las contribuciones de este enfoque educativo al proporcionar una base de partida más amplia para el desarrollo de las potencialidades, el aprendizaje y la construcción del conocimiento. Los aportes se traducen en una práctica docente innovadora que afecta positivamente la integridad de estudiantes $y$ docentes en el proceso de aprendizaje basado en proyectos.

Palabras clave: TEORÍA INTELIGENCIAS MÚLTIPLES, MÉTODO BASADO EN PROYECTOS, ESTRATEGIAS PEDAGÓGICAS, EDUCACIÓN PRIMARIA, COSTA RICA, PANAMÁ.

Abstract: This article shows the scientific research results developed in the Master of Educational Psychology at the UNED (Universidad Estatal a Distancia). This research seeks to recognize the theoretical conceptualizations and methodological strategies used by first cycle teachers implementing the Theory of Multiple Intelligences in the curriculum in the Costa Rican educational system as well as in the neighboring country of Chiriqui-Panama. The research methods guiding the study is basically qualitative and hermeneutic. Thus, the research was conducted for exploratory purposes, which used the application and analysis of in-depth semi-structured interviews to both teachers and experts, in order to gather samples through grounded theory, fieldwork observations, focus groups, and a broad theoretical and documentary study of the systems. The study provides a broad perspective on the possibilities and advantages of the Multiple Intelligence Theory in the educational system. The study remains the integrity of both students and teachers positively; it provides a broader and stronger support for the development of human potential, learning, and construction of knowledge. This is evident in the empirical results of this study, particularly in the teaching and evaluative strategies.
\end{abstract}

Keywords: MULTIPLE INTELLIGENCES THEORY, PROJECT BASED METHODS, TEACHING STRATEGIES, PRIMARY EDUCATION, COSTA RICA, PANAMA.

\footnotetext{
Investigadora del Instituto de Investigaciones Psicológica y Docente de la Escuela de Psicología de la Universidad de Costa Rica.
}

Dirección electrónica: aida.mainieri@ucr.ac.cr

Artículo recibido: 8 de abril, 2014

Enviado a corrección: 29 de julio, 2014

Aprobado: 8 de diciembre, 2014 


\section{Introducción}

El presente artículo científico responde a los resultados del proyecto de investigación que lleva su nombre, desarrollado en el marco de la Maestría en Psicopedagogía y el Posgrado de la Universidad Nacional de Educación a Distancia (UNED) y concluido en su fase final en el 2011. Fue presentado en el VII Congreso Universitario Centroamericano en León, Nicaragua y en el III Simposio Internacional y VII Nacional sobre los derechos de la Niñez y la Adolescencia. Sus resultados finales también fueron objeto de participación en VIII International Conference on Interdisciplinary Social Sciences, en Charles University Praga, en agosto 2013.

Es fundamental, para todo proceso educativo actualizado y de calidad, investigar las estrategias metodológicas que utilizan los y las docentes para favorecer el desarrollo de las Múltiples Inteligencias en niños y niñas, porque su incorporación en la enseñanza formal propicia a un enfoque psicoeducativo que permite la aplicación práctica y provechosa de los últimos avances en las teorías de la inteligencia, reuniendo importantes aportes del paradigma cognitivo que actualmente incorpora grandes avances en las Neurociencias, como se observará, y enfocando el desarrollo integral de los individuos y la óptima potenciación de sus habilidades. Recientemente se incursiona en aplicaciones que refuerzan el aprendizaje, su contraparte evaluativa y desarrollo de los estudiantes, lo que impacta el currículo alrededor del mundo. Estos hechos motivaron que el autor de la Teoría de las Inteligencias Múltiples (TIM), Howard Gardner, recibiera el Premio Príncipe de Asturias en el 2011.

Partiendo de un enfoque psicoeducativo actualizado se prioriza que los programas educativos deben favorecer el máximo desarrollo de aspectos intelectuales, sociales y espirituales, así como habilidades para resolver problemas, ser creativos y lograr productos personales, académicos y culturales.

De acuerdo con esta perspectiva, el rol del educador estaría dirigido a potenciar las capacidades de niños y niñas, lo que encuentra gran sentido en el desarrollo de las diferentes áreas de expresión, al estilo de las Inteligencias Múltiples (IM) y de sus exitosas aplicaciones (Gardner, Feldman y Krechevsky, 1998). El Docente, en su papel de educador, debe potenciar al máximo cada una de las inteligencias favoreciendo ambientes idóneos y experiencias nuevas a los educandos, para que estos puedan descubrir en sí mismos sus destrezas y habilidades; paralelamente, ejercitarlas, logrando así motivar, descubrir y despertar, en cada individuo, su mayor potencial. 
Por otra parte, las críticas a las maneras tradicionales de transmisión del conocimiento, han adquirido mucha más fuerza, ante los requerimientos de una formación que permita afrontar la rápida desactualización de los conocimientos, la integración de nuevas tecnologías en constante renovación en todos los campos y la necesidad de garantizar aprendizajes efectivos y relevantes que aporten al desarrollo de las potencialidades de cada individuo y así, de su sociedad. Las circunstancias actuales determinan nuevos retos, el estudiantado de hoy necesita ser más seguro y autónomo, lo cual nos obliga aún más a proveerles de mejores herramientas para su adecuado desarrollo.

No obstante, los avances en este campo son lentos en América Latina y sobre todo en los niveles básicos, donde es más frecuente encontrar prácticas educativas centradas en el almacenamiento de información más que en el desarrollo de las capacidades para procesarla y los énfasis están puestos en la pasividad más que en la actividad de los sujetos, lo que es bastante reconocido entre los educadores mismos. Los Educadores, como responsables del aprendizaje, raramente prestan atención a las interacciones y factores que influyen en la capacidad de motivarse y aprender de sus estudiantes. Los espacios escolares, a su vez, no acostumbran utilizarse como un medio que favorece las relaciones entre estudiante con sus docentes, entre estudiantes y con el conocimiento, sino que se pretende que este último sea transmitido.

Sin embargo, a pesar del predominio de las pedagogías tradicionales, existen en la mayoría de los países de la región experiencias innovadoras que apuntan a la modificación de las relaciones docente/estudiante, que se desenvuelven en las escuelas como ámbito de comunicación, donde los conocimientos se construyen en una dinámica que involucra experiencias, interacciones, contextos y saberes, que provienen de los distintos actores de los procesos de aprendizaje. En función de lo anterior, el enfoque de las IM es una opción viable que puede optimizar el aprendizaje de lo/as educandos y es lo que se pone en evidencia en esta investigación.

Fue desarrollada en San José-Costa Rica en una primera fase, luego se dio una réplica de la misma en Chiriquí Panamá; no obstante, se refieren aquí los procedimientos y resultados para Costa Rica.

La profundización teórica realizada, pasa por una conceptualización de la inteligencia y su origen en estudios genéticos, heredabilidad o influencia del ambiente en la misma; la teoría de la canalización genética, la de la plasticidad cerebral y sus bases en los últimos hallazgos de las Neurociencias; revisión de la obra de Howard Gardner, autor de la TIM, y su 
equipo de trabajo, además de gran parte de los autores en teorías del aprendizaje, más influyentes del paradigma cognitivo; asimismo se refiere el Método Basado en Proyectos; no obstante aquí se repasan en forma sumamente breve, en ese mismo orden en el apartado de referentes teóricos, seguido por la metodología empleada, resultados y conclusiones más relevantes.

\section{Referentes teóricos}

\subsection{Conceptualización del término "inteligencia"}

En el origen etimológico de la palabra "inteligencia" se encuentra que proviene de las raíces: "inter" que significa entre y "eligere" que se refiere a escoger. En ese sentido y según la define Antunes (2002), se puede decir que es la capacidad cerebral por la que conseguimos comprender las cosas eligiendo el mejor camino.

Así, como proceso mental, la inteligencia humana no es una realidad fácilmente identificable, sino un instrumento utilizado para estimar, explicar o evaluar algunas diferencias conductuales entre las personas: éxitos, fracasos, modos de relacionarse con los demás, proyecciones de vida, desarrollo de talentos, notas educativas, resultados de test cognitivos, etc., lo que refiere una capacidad para resolver problemas cotidianos y generar productos válidos para la sociedad, adaptarse y competir socialmente, como la define Lupiañez (2009); la persona puede entonces expresar lo que piensa y siente además de actuar y conducirse, lo que permite que esa capacidad se pueda medir a través de tests que deben ser confiables y válidos. No obstante, los científicos no han podido ponerse de acuerdo en cuanto a qué denominar una "conducta inteligente".

Según Gardner, "para la mayoría de la sociedad occidental la inteligencia es un constructo o capacidad que se puede medir mediante un conjunto de preguntas y respuestas breves, presentadas de palabra o por escrito" (2001, p.143), definición que se refiere al auge que ha tenido el enfoque en diversos modelos psicométrico de la inteligencia a los que él, posteriormente, ha reaccionado fuertemente en contra.

Dada la complejidad de definir "la inteligencia", así como la imposibilidad de comprenderla en ausencia de la amplia perspectiva de prácticas en que se encuentra involucrada, se realiza un recorrido por la gama de conceptualizaciones que se ofrecen, partiendo desde sus orígenes en términos de estudios genéticos, la polémica herencia 0 ambiente, la teoría de la canalización genética, la de la plasticidad cerebral, teorías mediacionales en el aprendizaje, modelos psicométricos, hasta llegar a la conceptualización 
de la multiplicidad intelectual de Gardner. Este recorrido se realiza siguiendo los pasos y la perspectiva que el mismo Gardner plasma en sus textos, quién se ha interesado y dedicado al estudio de todo ello.

2.1.1 Origen (estudios genéticos): Estos parten del principio de que los individuos somos seres bio-psico-sociales y concentrándose en los aspectos biológicos entran en la gran polémica que se encuentra a la base del origen de las cualidades humanas, son producto ¿de la herencia o del ambiente?

Con los descubrimientos de los genetistas se comprueba que el aspecto biológico resulta trascendental para el desarrollo y manifestación de habilidades, sugiriéndose que deben intensificarse las investigaciones acerca de la potenciación de las mismas en los diferentes grupos humanos y períodos históricos, sin embargo, no han respondido a muchos de los interrogantes acerca de la inteligencia.

Tal como lo menciona Gardner (1994, p.39) "somos organismos vivos, y, en un sentido todo lo que logremos será codificado en nuestro material genético" de manera que "la distinción entre el genotipo (código genético de un individuo), estructura del organismo, y el fenotipo (manifestación externa del genotipo), características visibles, es fundamental para considerar el perfil conductual e intelectual de cualquier individuo". No obstante, el estudio de habilidades humanas complejas, como la solución de ecuaciones o el aprendizaje de un idioma, relacionados con el componente genético y la expresión fenotípica de un individuo, es muy vago; por otra parte, se comprende que estas no pueden ser estudiadas experimentalmente en el laboratorio, "más aún, en vez de estar relacionadas con un gen específico o un conjunto pequeño de genes, todo rasgo complejo refleja muchos genes, de los cuales un buen número será poliformo, es decir, que permite logros distintos en diversos ambientes" (Gardner, 1994, p.39).

2.1.2 Inteligencia: ¿herencia o ambiente?: El dilema que existe y ha existido siempre entre los psicólogos sobre la definición de la inteligencia se presenta también en el debate sobre la función que desempeña la herencia y el ambiente en el desarrollo de la misma.

Es casi imposible separar la inteligencia "que se encuentra en los genes" de la "que se debe a la experiencia". En la actualidad, la mayoría de los psicólogos cree que las diferencias se deben a ambos aspectos, tal vez en igual proporción tanto entre adultos como niños. "Los genes no fijan la conducta. Más bien, establecen una variedad de reacciones posibles a la gama de experiencias factibles que el ambiente provee" (Weinberg, 1989, 
p.101) Las influencias ambientales lo incluyen todo, desde la salud de la madre durante el embarazo hasta la calidad de la enseñanza que recibe el niño o la niña.

Al igual que cualquier otra aptitud, siempre es posible mejorar las destrezas cognoscitivas. La inteligencia es el estado actual de cosas, influida por las experiencias previas, y abierta a los cambios. Incluso si la inteligencia fuese un potencial limitado sería de cualquier forma considerable y supondría un desafío para todos.

\section{Teoría de la canalización genética}

Ahondando en los aspectos biológicos del ser humano, se ha hecho oportuno indagar en la neurobiología, subdisciplina de la biología, y la neurociencia, entendiendo esta última como el estudio de las neuronas, células del sistema nervioso, y de la forma en que estas se organizan en circuitos funcionales que procesan la información y mediatizan el comportamiento. Para mayor especificidad, se incluyen en los estudios analizados aspectos de neuroanatomía, neurofisiología y neuropsicología, con la intención de obtener resultados más provechosos. Pues según, Howard Gardner (1994, p.41), "el conocimiento acerca del sistema nervioso se está acumulando con tanta rapidez como el conocimiento de la genética, y los resultados están mucho más cercanos, a los fenómenos de la cognición y de la mente".

Conrad Hal Waddington, según Nuñez (1981), uno de los fundadores de la biología de sistemas, biólogo del desarrollo, paleontólogo y genetista escocés, quien acuñó el concepto de canalización genética como la capacidad de un organismo para producir el mismo fenotipo en varios medios distintos e Ivan Ivánovich Shmalgauzen, morfólogo y embriólogo evolutivo ruso, quien acuñó el término de plasticidad fenotípica o norma de reacción como la capacidad de un organismo con un genotipo dado de cambiar su fenotipo en respuesta a cambios en el entorno, buscaron la manera de integrar la biología del desarrollo en la teoría evolutiva, siendo uno de los precedentes principales de la moderna evo-devo (Evolutionary Developmental Biology), es decir, Biología Evolutiva del Desarrollo.

Fue así que Gardner (1994), en su libro "Estructuras de la Mente", considera oportuno iniciar el tema de la Neurobiología, entendiendo la flexibilidad y hallazgos que apoyan la relativa plasticidad del sistema nervioso durante las primeras fases del desarrollo como las líneas de investigación que ayudan a iluminar las habilidades y operaciones que exhiben los seres humanos. Cabe mencionar que las conclusiones que se han obtenido con respecto a estos temas han sido el resultado de la investigación con animales, vertebrados e invertebrados, así como con el aporte de otros colegas de Gardner. 
Con respecto a la canalización, Gardner opina que el sistema nervioso crece en forma "delicadamente sincronizada" y programada,

Lejos de representar una reunión aleatoria o accidental, las conexiones nerviosas que se logran en realidad reflejan el más elevado grado de control bioquímico. Uno observa la sorprendente secuencia epigenética en que cada paso en el proceso establece la base de trabajo para la siguiente y facilita su desarrollo (1994, p. 41).

\section{Teoría de la plasticidad cerebral}

\subsection{El ambiente los estímulos y la estimulación adecuada}

La etapa del desarrollo del ser humano que va desde la concepción el nacimiento hasta los 6 a 7 años de vida es considerada como la etapa más significativa en la formación del individuo, así como en los años subsiguientes se sucede un período de gran relevancia, en este sentido, ya que el individuo cuenta con la posibilidad de elevar (o de perder) su potencial antes de que este se consolide en la adolescencia y adultez propiamente dicha. En ese período se estructuran las bases fundamentales de las particularidades físicas, neurológicas y aspectos psicológicos de la personalidad, que se perfeccionarán y consolidarán en las etapas posteriores (Álvarez, 2001).

En esos años de pleno proceso de formación y maduración de estructuras bio-psicofisiológicas y sociales es particularmente significativa la estimulación que pueda ofrecerse, ya que será la que de manera más determinante afecte el desarrollo integralmente. Entre más tierna es la criatura humana, mayor será su plasticidad o facilidad con la que se marcan las huellas de la experiencia vivida que van estructurando las bases de su integridad neurológica y psicosocial (Álvarez, 2001). La plasticidad cerebral, en etapas tempranas, está determinada por la ausencia de comportamientos (voluntarios) predeterminados al nacer y las capacidades innatas para aprender, factores que deben ser oportuna y adecuadamente tratados, propiciando la estimulación que favorece el desarrollo. Esto es especialmente importante en poblaciones de alto riesgo biológico y social, así como en niños y niñas con algún grado de discapacidad.

El Dr. Hernán Montenegro citado por Osorio y Oblitas (1978) como reconocido investigador chileno, con gran claridad ha definido la estimulación adecuada como el conjunto de acciones tendientes a proporcionar al niño las experiencias que éste necesita desde su nacimiento, para desarrollar al máximo su potencial psicológico. Esto se logra a través de la presencia de personas y objetos, en cantidad y oportunidad adecuadas y en el 
contexto de variada complejidad, que generen en el niño un cierto grado de interés y actividad despertando en él o ella ese "instinto del saber" al que se refieren algunos constructivistas, condición necesaria para lograr una relación dinámica con su medio ambiente y un aprendizaje efectivo.

Así, estimulación adecuada es toda actividad oportuna, adecuada, sistemática, continua, gradual, bien dirigida cualitativa y cuantitativamente, que enriquece al niño/niña en su desarrollo físico, psíquico y espiritual, contemplando su entorno sociocultural con el propósito de potenciar un adecuado nivel de desarrollo integral. Pero por sobre todo ello, está la calidad humana que se manifiesta en: la atención concentrada, el afecto positivo y sincero, la comunicación íntima, el soporte moral y la contención afectiva brindada por los padres-cuidadores-educadores del niño; como bien lo expresó María Montessori "la relación afectiva es el hilo conductor del aprendizaje" e igualmente apela a ello Jean Piaget cuando refiere una equivalencia entre lo que el juego es para el niño como lo que el trabajo es para el hombre o mujer (1975).

\subsection{Principios de la plasticidad}

Asimismo, Gardner (1994, p. 43) se interesó por los principios de la plasticidad alrededor del desarrollo prenatal, natal, posnatal y niñez temprana. Sus resultados ponen en evidencia cinco principios como los más influyentes en el desarrollo de un organismo joven que se detallan a continuación:

1. Máxima flexibilidad: el sistema nervioso puede adaptarse mejor a los daños graves o a la alteración experimental. Algún tiempo después de un daño, el mismo sistema puede diseñar una ruta o conexión alterna que puede ser adecuada; pero si la herida o alteración ocurre demasiado tarde durante el desarrollo, las células apropiadas se conectarán aleatoriamente o se atrofiarán sin restricción.

2. Períodos críticos: parece que los puntos más vulnerables de un organismo ocurren durante estos periodos sensitivos. Parece ser que un daño irreversible al sistema nervioso central puede ocurrir con mucha probabilidad en tal periodo crítico; a la inversa, un desarrollo rápido ocurre si se dan unas condiciones apropiadas durante tal periodo crítico.

3. Imparcialidad: el grado de flexibilidad difiere a través de la región del sistema nervioso en que uno está interesado. Las regiones que se desarrollan más tarde en la infancia, como los lóbulos frontales o el cuerpo calloso, resultan ser más maleables que las que 
se han desarrollado en los primeros días y semanas de vida, como la corteza sensorial primaria. En efecto, cuando se trata de las capacidades humanas más complejas, como el lenguaje, el individuo puede soportar incluso daño masivo, como la extirpación de un hemisferio completo, en sus primeros años de vida y todavía adquirir la capacidad de hablar en forma razonablemente normal; esta recuperación indica que grandes porciones de la corteza se mantienen imparciales (y por tanto disponibles para usos diversos) durante la niñez temprana.

4. Factores que intervienen o regulan el desarrollo: un organismo no se desarrolla de manera normal a menos que esté expuesto a determinadas experiencias. Si falta el estímulo apropiado, o si éste es inadecuado, no se lograrán las metas usuales del desarrollo y el animal o individuo no realizará sus funciones apropiadamente en su ambiente.

5. Efectos a largo plazo de los daños al sistema nervioso: en tanto que algunos daños provocan efectos inmediatos evidentes, otros pueden ser invisibles al principio. El daño temprano al cerebro también puede estimular determinadas reorganizaciones anatómicas que en última instancia podrían ser contraproducentes. Por ejemplo, se pueden formar conexiones que permitan al animal o individuo realizar tareas esenciales en este momento, pero que más tarde serían inútiles para que emergieran habilidades necesarias.

En síntesis, Gardner (1994, p.44) considera que "la determinación (o canalización) ayuda a asegurar que la mayoría de los organismos podrán realizar las funciones de la especie en la forma normal; y que la flexibilidad (o plasticidad) permite la adaptación a circunstancias cambiantes, incluyendo ambientes anormales o daños tempranos. Es claro que si uno debe sufrir un daño, es mejor que sea temprano; pero quizá toda desviación del camino normal del desarrollo tiene su precio".

\subsection{Proliferación de los procesos y sinapsis celulares:}

El concepto de plasticidad neuronal se refiere a la capacidad del sistema nervioso de remodelar los contactos entre neuronas y la eficiencia de las sinapsis. La plasticidad neuronal puede explicar ciertos tipos condicionamientos y de capacidad de aprendizaje.

El establecimiento de sinapsis se realiza con el crecimiento del axón hacia una célula "blanco". Este proceso es guiado por cambios electroquímicos que liberan las células he indican el trayecto extensivo del axón hasta tomar contacto sináptico. 
Para determinar la influencia que tienen los estímulos en el desarrollo de los organismos, se han realizado diversos estudios con roedores. Mark Rosenzweig, psicólogo, y un grupo de colegas de la Universidad de California en Berkeley realizaron un estudio, a principio de los años sesenta, en donde dividieron un grupo de roedores en dos subgrupos. Un grupo tenía suficiente comida, ruedas y escaleras; y otro rodeado con suficiente comida nada más. Al concluir el estudio, observaron que los roedores expuestos a ruedas y escaleras se desempeñaron mejor en diversas tareas conductuales que los otros.

Luego de 80 días de observación, los investigadores sacrificaron a los roedores y determinaron, según Gardner (1994, p.45), que

las cortezas cerebrales de las ratas enriquecidas pesaron $4 \%$ más que las ratas empobrecidas (aunque estaban más gordas). Más importante todavía fue que el mayor aumento en el peso cerebral ocurrió en las partes del cerebro que sirven para la percepción visual, quizá las que fueron estimuladas de forma particular en el ambiente enriquecido.

Con este y otros estudios se confirma la idea de que, entre más enriquecedor sea el ambiente en que se desenvuelve y se desarrolla un organismo más refinado será el aprendizaje que el mismo adquiera; lo cual se evidencia también en el tamaño de su cerebro. Gardner (1994.) respalda esta idea, con lo demostrado por William Greenough "los cambios regionales mayores que acompañan las diferencias en la experiencia están asociados con cambios en las neuronas en la cantidad, patrón y cualidades de las conexiones sinápticas."

Oskar Vogt (citado por Gardner, 1994.), físico y neurólogo alemán, desarrolló un gran interés por localizar el "origen del genio" intelectual. Por ello, durante algunos años dirigió el Instituto de Investigación Cerebral en Moscú. Allí se analizaron los cerebros de distintas personalidades de la Unión Soviética; Gardner (1994, p.45) menciona "Un pintor cuyo cerebro estudiaron mostró una cuarta capa muy grande de células en su corteza visual, y un músico con perfecta entonación desde la niñez temprana tenía una región análogamente grande de células en la corteza auditiva."

Como sabemos, el cerebro humano es una estructura sumamente compleja que posee una cantidad impresionante de células nerviosas, las neuronas; durante el desarrollo fetal se van generando y van estableciendo conexiones muy precisas para encargarse de funciones muy determinadas, algunas prefijadas y otras no. Según Shatz (1992), se ha comprobado 
que el aumento de células en las diferentes áreas del cerebro se debe a la actividad neuronal que haya tenido y tenga un individuo

El cerebro del recién nacido tiene prácticamente el mismo número de neuronas que el cerebro del adulto. Si todo funciona adecuadamente, el interruptor biológico no se para en el nacimiento y a medida que crece progresa el desarrollo humano aumentando el tamaño de las células nerviosas y sus ramificaciones (axones y dendritas) que le permiten realizar numerosas conexiones cada vez más complejas y precisas, en un cerebro sano. Si hay lesiones, las rutas y las conexiones o las propias neuronas se ven afectadas o exterminadas. El desarrollo del cerebro es fundamental, en el crecimiento y funcionamiento neuronal en razón de las conexiones que van estableciendo, no es el aumento de número de células. (Shatz, citado en Nery, 2009, parr. 10)

Lo que sí nos confirman todos los estudios sobre desarrollo y cerebro, es que para que el cerebro sea funcional es necesaria la actividad neuronal, y la actividad neuronal se consigue a base de una estimulación mínima y adecuada.

\section{Teorías mediacionales reseñadas por Gimeno y Pérez (1996)}

Las teorías mediacionales son aquellas que están agrupadas en una familia en las que se da la mediación de una estructura cognitiva interna en el proceso de aprendizaje; ello se contrapone al conductismo tradicional que se enfoca en la conducta observable, considerando lo interno como una "caja negra" acerca de la cual no podemos conocer con certeza. Así es que a pesar de las notables diferencias entre las teorías psicológicas mediacionales, existen características comunes y fundamentales (Pérez, Alfaro, Arauz, Avendaño, y Rojas, 2000):

- La importancia de las variables internas.

- La consideración de la conducta como totalidad.

- La supremacía del aprendizaje significativo que supone reorganización cognitiva y actividad interna (Gimeno y Pérez, 1996).

Estas teorías cobran gran relevancia en el marco de las Inteligencias Múltiples de Gardner (2001); esto porque él se sirve de ellas y sus postulados parten del estudio y análisis de esa estructura. En este sentido, es posible encontrar cierto paralelismo con Piaget (1975) en términos de concebir las inteligencias directamente relacionadas con procesos de 
adaptación y evolución genética y, tal y como lo manifiesta, seguir sus pasos para lograr sus propios hallazgos.

\subsection{Teoría del Campo o corriente de la Gestalt}

Sus principales representantes son: Wertheimer, Kofka, Kohler, Wheeler, y Lewin (Gimeno y Pérez, 1996, p.41). Considera la conducta como una totalidad organizada de modo que en los fenómenos de aprendizaje y conducta, el todo, es más que la suma y yuxtaposición lineal de las partes. Las relaciones que confluyen entre los elementos forman una totalidad significativa, definiendo las propiedades y la conducta del individuo.

Basados en estos supuestos definen la teoría de campo, como el mundo psicológico total en que opera la persona en un momento determinado. Este conjunto de fuerzas que interactúan alrededor del individuo, originan los procesos de aprendizaje; que deben contener sentido y significado. Además de las manifestaciones observables en el interior del individuo se desarrollan procesos cognitivos de discernimiento y de búsqueda intencional de objetivos y metas. El sujeto reacciona a la realidad según su percepción subjetiva. De acuerdo a su comprensión de las situaciones, y al significado que dé a los estímulos, así será su conducta en ese preciso momento.

El pilar fundamental en que se sustenta la teoría de campo es la comprensión significativa de las estructuras cognitivas. La motivación intrínseca de los requerimientos y exigencias del individuo es lo que origina el aprendizaje.

\subsection{Psicología Genético-Cognitiva}

Su precursor fue Piaget y la Escuela de Ginebra, otros representantes son: Inhelder, Bruner, Flavell, Ausubel (Gimeno y Pérez, 1996, p.43), las teorías, principios y planteamientos de esta corriente continúan siendo de gran provecho y aplicabilidad en el proceso de enseñanza aprendizaje; aun hoy día continúan desarrollándose y sus investigaciones son imprescindibles para comprender el aprendizaje humano, el funcionamiento de la estructura interna y su génesis.

\subsection{El Aprendizaje Significativo de Ausubel}

Según Pérez, Alfaro, Arauz, Avendaño, y Rojas (2000), Ausubel centra su estudio en el aprendizaje escolar, con énfasis en los niveles superiores. El aprendizaje significativo (por recepción o descubrimientos) debe contener un cuerpo organizado de material significativo, 
para que el conocimiento se adquiera, es necesario contar con determinadas condiciones que Ausubel identifica así: "La esencia del aprendizaje significativo reside en que las ideas expresadas simbólicamente son relacionadas de modo no arbitrario, sino sustancial con lo que el alumno ya sabe. El material que se aprende es potencialmente significativo para él" (Pérez, et al., 2000, p. 47).

\subsection{La Escuela Dialéctica}

Entre sus representantes más significativos están: Vigotsky, Luria, Leontiev, Rubinstein, Liublinckata, Talzina, Galperin (Pérez, Alfaro, Arauz, Avendaño, y Rojas, 2000): Su primer aporte es la concepción dialéctica de la relación entre aprendizaje y desarrollo. La cognición está en función de la comunicación y del desarrollo. El desarrollo, por otra parte, es el resultado del intercambio entre la información genética y el contacto experimental con el medio.

\subsection{La escuela de Wallon}

La psicología genético-dialéctica francesa de Wallon (Gimeno y Pérez, 1996), confirma los principales postulados de la escuela soviética. Él tampoco concibe el aprendizaje sin su ubicación dentro del proceso de desarrollo. Lo importante era explicar el paso de lo orgánico a lo psicológico. Se da una génesis, presidida y condicionada por la penetración social. En este paso intervienen cuatro elementos: la emoción, imitación, motricidad y el socius (Gimeno y Pérez, 1996, 52).

\subsection{El aprendizaje como procesamiento de información}

Logró su auge al resaltar la importancia de las estructuras internas que mediatizan las respuestas. Bajo esta corriente hay neoconductistas y seguidores del aprendizaje cognitivo, entre los que se encuentra el trabajo de Gagné, según Gimeno y Pérez (1996) quien define ocho tipos de aprendizaje; desde los más simples hasta los más complejos. Aunque afirma la necesidad de todos, le da mayor importancia al aprendizaje de conceptos, principios y solución de problemas, por ser los más utilizados en la escuela. Otros de sus representantes más destacados citados por Gimeno y Pérez (1996) son: Newell, Shaw y Simón. Este modelo considera al hombre como un procesador activo de información, cuya función es recibir información, elaborarla, acumularla, recuperarla y utilizarla. Supone que el organismo no responde directamente al mundo real sino a la propia y mediada representación subjetiva 
del mismo. Esta mediación selecciona, transforma y frecuentemente distorsiona el estímulo recibido; su base son los procesos internos, mediadores entre el estímulo y la respuesta.

\subsection{Relaciones entre teorías de aprendizaje y la práctica educativa}

El concepto de aprendizaje es requisito para una elaboración teórica sobre la enseñanza. Tanto la teoría como la práctica didáctica necesitan un cuerpo de conocimientos, sobre los procesos de aprendizajes, que deben contar con lo siguiente:

- Abarcar integralmente los procesos y clases de aprendizaje.

- En todo momento debe estar presente la realidad. En cualquier ambiente, laboratorio, aula escolar o en condiciones de la vida cotidiana. Por tanto, ser objetivo y realista durante el proceso de investigación y al inferir los resultados.

Las teorías del aprendizaje proporcionan información básica pero no suficiente para organizar la teoría de la práctica y la práctica de la enseñanza. A esta disciplina teórico práctica, le correspondería la organización de las condiciones externas e interacción y control con las internas del individuo. El objetivo del aprendizaje es lograr el desarrollo y perfeccionamiento de las estructuras cognitivas y conductuales del estudiante atendiendo la motivación, atención, asimilación, organización, recuperación y transferencia, además de las complejas redes de intercambio social, cultural y material dentro y fuera del recinto escolar, que son imprescindibles para comprender y orientar los procesos de aprendizaje y desarrollo, ya que sólo así se logra el desarrollo integral del educando (Pérez, et al., 2000).

\section{La Teoría de las Inteligencias Múltiples de Howard Gardner}

Gardner nació en Scranton, Pennsylvania, en 1943, poco después que su familia emigró a Estados Unidos, huyendo del régimen nazi. De niño era buen alumno y rendía bien en las pruebas. Era un proverbial muchacho judío que no soportaba la visión de la sangre y que esperaba convertirse en abogado.

No fue hasta el final de sus estudios en la Universidad de Harvard, que decidió dedicarse al estudio de la psicología; después de conocer a Jerome Bruner, leer sus obras y la de su maestro Jean Piaget cuando se dedicó a especializarse en Psicología Cognitiva y Evolutiva", proceso en el que "me sorprendió: casi todos los especialistas de este campo daban por sentado que el pensamiento científico y la trayectoria de la ciencia representaban las cumbres o estados finales del desarrollo cognitivo del hombre"; sin embargo en lo que 
respecta al desarrollo, "preguntándome cuál era el desarrollo humano óptimo, me fui convenciendo de que los especialistas de este campo tenían que prestar mucha más atención a las aptitudes y capacidades de los pintores, los escritores, los músicos, los bailarines y otros artistas" (Gardner, 2001, p.40) y consideró que eran tan cognitivas como las que la psicología cognitiva atribuían a los matemáticos y los científicos.

Ante esto dice Gardner (2001, p.40) "Piaget y sus colegas habían esclarecido el desarrollo cognitivo de los niños estudiando el camino que seguían hasta llegar a pensar como científicos. Siguiendo esta línea paralela, mis colegas y yo estudiamos cómo llegan los niños a pensar y actuar como artistas. Y, con este objetivo, empezamos a diseñar experimentos y estudios de observación para esclarecer las etapas y fases del desarrollo del talento artístico."

Sus líneas de investigación se han centrado en el análisis de las capacidades cognitivas en menores y adultos, a partir de lo cual ha formulado la "Teoría de las inteligencias múltiples", basada en que cada persona tiene -por lo menos- ocho inteligencias u ocho habilidades cognoscitivas.

Actualmente, este neuropsicólogo, es investigador de la Universidad de Harvard, codirector del Proyecto Zero en la Escuela Superior de Educación de Harvard, al que ha estado afiliado desde sus inicios en 1967 (lbíd) donde además se desempeña como profesor de Educación y de Psicología; también es profesor de Neurología en la Facultad de Medicina de la Universidad de Boston. Asimismo, participa en el Good Work Project, destinado a mejorar la calidad y la autoestima profesionales de la educación, en el que se toman en consideración, fundamentalmente, los factores de la excelencia y la ética (Instituto Innova, 2008) .

Gardner ha sido galardonado con el premio "Genius" Mc Arthur (1981). En 1983 presentó su teoría en el libro Frames of Mind: The Theory of Multiple Intelligences y, en 1990, fue el primer estadounidense que recibió el Premio de Educación Grawmeyer de la Universidad de Louisville y posee catorce doctorados honoris causa.

Se opone a los pensamientos de Spearman y otros psicometristas sobre su concepción de inteligencia como una capacidad unitaria de razonamiento lógico Espinoza, 1997). Se basó en L. L. Thurstone y otros psicometristas (Sternberg y Powell, 1989) que decían que "el intelecto humano abarca varias habilidades psíquicas" (Gardner, Kornhaber y Wake, 2000, p.174). Gardner postula la existencia de varias inteligencias relativamente autónomas.

Critica la idea de la existencia de una sola inteligencia, a través de las pruebas 
psicométricas. En 1993 publicó su gran obra Las Inteligencias Múltiples; en 1997, Mentes extraordinarias. Hasta la fecha ha escrito quince libros: Arte, mente y cerebro; La mente no escolarizada; Educación artística y desarrollo humano y La nueva ciencia de la mente, son algunos de los títulos, y varias centenas de artículos.

Expresa que la inteligencia se desenvuelve como un sistema de capacidades para resolver problemas y elaborar productos valiosos en diversos contextos culturales, en su conjunto, la inteligencia se manifiesta:

- Como autónoma de otras capacidades humanas.

- Como una base para la realización de operaciones de información y procesamiento.

- Como una realidad distinta según las etapas de nuestro desarrollo, lo que asegura una historia evolutiva de cada ser humano (Gardner, 2001).

\section{1 ¿Qué son las Inteligencias Múltiples?}

El conocimiento sobre las funciones y los alcances de nuestra mente siguen siendo parciales. Según Gardner, Feldman y Krechevsky (2001), no se ha llegado todavía a desentrañar todos los misterios que encierra el órgano central de nuestro sistema nervioso.

Estudios neurobiológicos señalan que el cerebro posee varias zonas relacionadas con determinados espacios de cognición. Según Gardner estas zonas serian ocho, y así cada persona tendría ocho puntos distintos determinantes de diferentes inteligencias, a las que denomina "inteligencias múltiples" (Antunes, 2002).

Asimismo, la posición de estos teóricos ante la inteligencia, constituyó una de las fuentes que sirvió a Goleman (2004) para formular su teoría de la Inteligencia Emocional, quien en realidad sustenta su trabajo particularmente en las inteligencias intrapersonal e interpersonal de Gardner. Por lo demás, según Goleman (2004), Gardner fue uno de los asesores para la formulación final de La inteligencia Emocional.

La teoría de las Inteligencias Múltiples es una teoría del funcionamiento cognitivo y propone que cada persona posee las ocho inteligencias, la mayoría de las personas pueden desarrollar cada inteligencia hasta un nivel adecuado de competencia, las inteligencias por lo general trabajan juntas de maneras complejas, hay muchas maneras de ser inteligentes dentro de cada categoría según se explica ampliamente en Gardner, 2001: 


\subsubsection{Inteligencia Musical}

Es la capacidad de percibir, discriminar, transformar y expresar las formas musicales. Incluye la sensibilidad al ritmo, al tono y al timbre. Está presente en compositores, directores de orquesta, críticos musicales, músicos, luthiers y oyentes sensibles, entre otros. Los niños que la evidencian se sienten atraídos por los sonidos de la naturaleza y por todo tipo de melodías. Disfrutan siguiendo el compás con el pie, golpeando o sacudiendo algún objeto rítmicamente.

\subsubsection{Inteligencia Corporal-Cinestésica}

Es la capacidad para usar todo el cuerpo en la expresión de ideas y sentimientos, y la facilidad en el uso de las manos para transformar elementos. Incluye habilidades de coordinación, destreza, equilibrio, flexibilidad, fuerza y velocidad, como así también la capacidad cinestésica y la percepción de medidas y volúmenes. Se manifiesta en atletas, bailarines, cirujanos, y artesanos, entre otros. Se la aprecia en los niños que se destacan en actividades deportivas, danza, expresión corporal y/o en trabajos de construcciones utilizando diversos materiales concretos. También en aquellos que son hábiles en la ejecución de instrumentos.

\subsubsection{Inteligencia Lingüística}

Es la capacidad de usar las palabras de manera efectiva, en forma oral o escrita. Incluye la habilidad en el uso de la sintaxis, la fonética, la semántica y los usos pragmáticos de lenguaje (la retórica, la mnemónica, la explicación y el metalenguaje). Alto nivel de esta inteligencia se ve en escritores, poetas, periodistas y oradores, entre otros. Está en los niños a los que les encanta redactar historias, leer, jugar con rimas, trabalenguas, y en los que aprenden con facilidad los idiomas.

\subsubsection{Inteligencia Lógico- Matemática}

Es la capacidad para usar los números de manera efectiva y de razonar adecuadamente. Incluye la sensibilidad a los esquemas y relaciones lógicas, las afirmaciones y las proporciones, las funciones y otras abstracciones relacionadas. Alto nivel de esta inteligencia se ve en científicos, matemáticos, contadores, ingenieros y analistas de sistemas, entre otros. Los niños que la han desarrollado analizan con facilidad planteos y problemas. Se acercan a los cálculos numéricos, estadísticos y presupuestos con entusiasmo. 
Las personas con una inteligencia lógica- matemática bien desarrollada son capaces de manejar el pensamiento abstracto utilizando la lógica y los números para establecer relaciones entre distintos datos. Destacan, por tanto, en la resolución de problemas, en la capacidad de realizar cálculos matemáticos complejos y el razonamiento lógico.

Ella implica una gran capacidad de visualización abstracta, el modo de pensamiento del hemisferio izquierdo y una preferencia por la fase teórica de la rueda del aprendizaje de Kolb, Rubin y Mclntyre (1974), aprendizaje basado en experiencias. Es por tanto una de las dos grandes privilegiadas de nuestro sistema educativo, junto a la lingüística.

\subsubsection{Inteligencia Espacial}

Es la capacidad de pensar en tres dimensiones. Permite percibir imágenes externas e internas, recrearlas, transformarlas o modificarlas, recorrer el espacio o hacer que los objetos lo recorran y producir o decodificar información gráfica. Presente en pilotos, marinos, escultores, pintores y arquitectos, entre otros.

\subsubsection{Inteligencia Interpersonal}

Es la capacidad de entender a los demás e interactuar eficazmente con ellos. Incluye la sensibilidad a expresiones faciales, la voz, los gestos y posturas y la habilidad para responder. Presente en actores, políticos, buenos vendedores y docentes exitosos, entre otros.

\subsubsection{Inteligencia Intrapersonal}

Refiere la posibilidad de acceder a la propia vida interior. Se le considera esencial para el autoconocimiento, que permita la compresión de las conductas y formas propias de expresión. Se encuentra muy desarrollada en teólogos, filósofos, psicólogos, entre otros.

\subsubsection{Inteligencia Naturalista}

Es la capacidad de distinguir, clasificar y utilizar elementos del medio ambiente, objetos, animales o plantas. Tanto del ambiente urbano como suburbano o rural. Incluye las habilidades de observación, experimentación, reflexión y cuestionamiento de nuestro entorno. La poseen en alto nivel la gente del campo, botánicos, cazadores, ecologistas, paisajistas, entre otros. También consiste en la interacción con las criaturas vivientes y el discernimiento de patrones de vida y fuerzas naturales. 


\subsubsection{Inteligencia Espiritual}

Es la inteligencia más reciente. Se presenta como la capacidad o sensibilidad para lo espiritual, o como un don para lo religioso, lo místico y lo trascendental. Es motivo de controversia dentro de las ciencias y en el mundo académico. Lo espiritual es entendido como efecto en los demás. Con frecuencia se considera que los grandes líderes religiosos como los budas históricos, Jesús, Santa Juana de Arco y Confucio, han alcanzado un nivel de conciencia, una conexión con el mundo, una victoria sobre el ego, que constituyen la meta de una existencia espiritual ejemplar (Gardner, 2001).

Estas inteligencias se traducen en aspectos de extrema relevancia, para el aprendizaje, por las implicaciones que puede tener en la elaboración de perfiles intelectuales, gestiones de desarrollo, análisis de biografías entre otros estudios. Estos aspectos pueden observarse en forma breve en la tabla 1, en la que pueden identificarse las relaciones entre el potencial intelectual en el que se destacan las personas, el estilo preferencial que favorece su aprendizaje y desarrollo, de acuerdo con las áreas de la inteligencia.

Tabla 1: Área en la que se destaca, lo que le gusta y como aprende mejor, un individuo, de acuerdo con cada tipo de inteligencia

\begin{tabular}{|c|c|c|c|}
\hline ÁREA & DESTACA EN & LE GUSTA & APRENDE MEJOR \\
\hline $\begin{array}{c}\text { LINGUISTICO- } \\
\text { VERBAL }\end{array}$ & $\begin{array}{l}\text { Lectura, escritura, narración, de } \\
\text { historias, memorización de fechas, } \\
\text { piensa en palabras. }\end{array}$ & $\begin{array}{l}\text { Leer, escribir, contar, } \\
\text { cuentos, hablar, } \\
\text { memorizar, hacer puzzles. }\end{array}$ & $\begin{array}{l}\text { Leyendo, escuchado y viendo palabras, } \\
\text { hablando, escribiendo, discutiendo, y } \\
\text { debatiendo. }\end{array}$ \\
\hline $\begin{array}{l}\text { LÓGICA- } \\
\text { MATEMÁTICA }\end{array}$ & $\begin{array}{l}\text { Matemáticos, razonamiento, lógica, } \\
\text { resolución de problemas, pautas. }\end{array}$ & $\begin{array}{l}\text { Resolver problemas, } \\
\text { cuestionar, trabajar con } \\
\text { números, experimentar. }\end{array}$ & $\begin{array}{l}\text { Usando pautas y relaciones, } \\
\text { clasificando, trabajando con lo } \\
\text { abstracto. }\end{array}$ \\
\hline ESPACIAL & $\begin{array}{l}\text { Lectura de mapas, gráficos, } \\
\text { dibujando, laberintos, puzzles, } \\
\text { imaginando cosas, visualizando. }\end{array}$ & $\begin{array}{l}\text { Diseñar, dibujar, construir, } \\
\text { crear, soñar despierto, } \\
\text { mirar dibujos. }\end{array}$ & $\begin{array}{l}\text { Trabajando con dibujos y colores, } \\
\text { visualizando, usando su ojo mental, } \\
\text { dibujando. }\end{array}$ \\
\hline $\begin{array}{l}\text { CORPORAL- } \\
\text { CINESTESICA }\end{array}$ & $\begin{array}{l}\text { Atletismo, danza, arte, dramático, } \\
\text { trabajos manuales, utilización de } \\
\text { herramientas. }\end{array}$ & $\begin{array}{l}\text { Moverse, tocar y hablar } \\
\text { lenguaje corporal. }\end{array}$ & $\begin{array}{l}\text { Tocando, moviéndose, procesando } \\
\text { información a través de sensaciones } \\
\text { corporales. }\end{array}$ \\
\hline MUSICAL & $\begin{array}{l}\text { Cantar, reconocer sonidos, recordar } \\
\text { melodías, ritmos. }\end{array}$ & $\begin{array}{l}\text { Cantar, tararear, tocar un } \\
\text { instrumento, escuchar } \\
\text { música. }\end{array}$ & $\begin{array}{l}\text { Ritmo, melodía, cantar, escuchando } \\
\text { música y melodías. }\end{array}$ \\
\hline INTERPERSONAL & $\begin{array}{l}\text { Entendiendo a la gente, liderando, } \\
\text { organizado, comunicando, } \\
\text { resolviendo conflictos, vendiendo. }\end{array}$ & $\begin{array}{l}\text { Tener amigos, hablar con } \\
\text { gente, juntarse con gente. }\end{array}$ & $\begin{array}{l}\text { Compartiendo, comparando, } \\
\text { relacionado, entrevistando, cooperando. }\end{array}$ \\
\hline INTRAPERSONAL & $\begin{array}{l}\text { Entendiéndose a sí mismo, } \\
\text { reconociendo sus puntos fuertes y } \\
\text { sus debilidades, estableciendo } \\
\text { objetivos. }\end{array}$ & $\begin{array}{l}\text { Trabajar solo, reflexionar, } \\
\text { seguir sus intereses. }\end{array}$ & $\begin{array}{l}\text { Trabajando solo, haciendo proyectos a } \\
\text { su propio ritmo, teniendo espacio, } \\
\text { reflexionando. }\end{array}$ \\
\hline NATURALISTA & $\begin{array}{l}\text { Entendiendo la naturaleza, haciendo } \\
\text { distinciones, identificando la flora y } \\
\text { la fauna. }\end{array}$ & $\begin{array}{l}\text { Participar en la naturaleza, } \\
\text { hacer distinciones. }\end{array}$ & $\begin{array}{l}\text { Trabajar en el medio natural, explorar } \\
\text { los seres vivientes, aprender acerca de } \\
\text { plantas y temas relacionados con la } \\
\text { naturaleza. }\end{array}$ \\
\hline
\end{tabular}

Fuente: Nicholson, 1998, traducido por Salvador. 
Las dos estrategias que emergen como alternativas fundamentales para la estimulación de las inteligencias múltiples, como se observará en los resultados, son el proceso de enseñanza aprendizaje a partir del perfil intelectual del estudiantado, y el método de enseñanza basado en proyectos.

\section{7. $\quad$ El Método Basado en Proyectos}

Los pilares de donde se sostiene la implementación del MP surgen del pensamiento de varios autores y modelos que coinciden en que la experimentación es la base del aprendizaje integral del ser humano según sus peculiaridades y potencialidades. Se inspira en el pilar los postulados filosóficos - psicológicos de Dewey, la teoría del Método de Proyectos de Kilpatrick y las bases del Paradigma Constructivista del aprendizaje.

John Dewey (UNESCO, 1993) fue el máximo exponente del movimiento de reforma en Estados Unidos, fue filósofo y líder del pragmatismo en la educación americana. Rescata la importancia de la experiencia para adquirir el conocimiento; el aprendizaje se produce por su asociación con el significado en la práctica, interactuando en el ambiente. Plantea un modelo que denominó "aprendizaje experiencial" y su disertación filosófica existencial sigue los siguientes principios:

La experiencia es primariamente un asunto activo - pasivo; no es primariamente cognoscitiva porque se introducen cambios por la acción directa.

$>$ La medida del valor de una experiencia se halla en la percepción de las relaciones o continuidades a que conduce.

$>$ El dualismo espíritu - cuerpo. Al tocar o ver las cosas (experimentación física) adquieren sentido (significado).

$>$ El espíritu y la ocupación (relaciones o conexiones). En el percibir deberá estimularse el juicio, la reflexión, la comprensión y análisis (procesos netamente intelectuales). Las relaciones no se pueden llegar a percibir sin la experimentación de las mismas.

> La reflexión es la aceptación de la responsabilidad por las consecuencias de la acción presente. El pensar es hacer un esfuerzo por descubrir el objeto y se establecer conexiones con el mismo.

$>$ Experiencia reflexiva y el ensayo - error. En la experimentación la persona ensaya una solución, esto lleva a algo desconocido para la persona, una aventura, una hipótesis que puede o no resultar y consecutivamente el conocimiento ya alcanzado estimula nuevos pensamientos y retos. 
Dewey plantea que para que saber si se produce una "experiencia reflexiva" debe cumplir con cinco requisitos: $1^{\circ}$ Perplejidad, confusión, duda; $2^{\circ}$ Anticipación por conjetura; $3^{\circ}$ Revisión cuidadosa (examen, inspección, exploración, análisis); $4^{\circ}$ Elaboración de una hipótesis y $5^{\circ}$ Plan de acción.

De acuerdo con esa perspectiva, el aprendizaje se inicia a partir de la vivencia de una experiencia concreta, esa experiencia es interpretada por el individuo a través de la reflexión, luego la conceptualiza mentalmente y la retiene para posteriormente aplicarla y transferirlas construyendo nuevos conceptos o formas de actuar en el ambiente psicosocial. Esta forma de aprendizaje da sentido a las palabras, ideas e información, adquiere significado y se fijan en el cerebro, internalizando hasta el compromiso de la acción personal directa en la transformación de su realidad.

Asimismo, en Estados Unidos, a finales del siglo XIX, el educador William H. Kilpatrick, filósofo educativo y colega de Richards y Dewey en la Universidad de Columbia, elaboró el concepto de "Método de Proyectos" y lo hizo famoso a nivel mundial en su artículo "The Proyect Method" (1918). El basó su propuesta en las ideas de Dewey antes expuestas, las interpreta e incluye nuevos aportes para la propuesta de la aplicación a través de una metodología.

El Buck Institute for Education (2010), por su parte, ha venido, desde hace más de veinticinco años, investigado sobre la metodología "Aprendizaje Basado en Proyectos" $(A B P)$, la que se enfoca en el beneficio de un aprendizaje práctico basado en experiencias reflexivas, lo que implica excusiones al campo, investigaciones de laboratorio y actividades interdisciplinarias, poniendo claro en que el aprendizaje es parte de las actividades sociales dentro de las diferentes culturas y comunidades y se alimenta de los conocimientos previos de las personas, aspectos que en muchas ocasiones no se toman en cuenta en la enseñanza formal. Es decir que la educación no solamente se da en las aulas y se mantiene en ella, sino que existen otros espacios en la vida de los estudiantes que les permiten aprehender nuevos conocimientos, habilidades y destrezas, así como darlos a conocer.

La Teoría de Aprendizaje Significativo de Ausubel, uno de los pilares del constructivismo (Gimeno y Pérez, 1996), sobre el que también se fundamenta esta metodología, se da a partir de experiencias que involucran a los estudiantes en proyectos complejos, basados en problemáticas reales; permitiéndoles desarrollar y aplicar habilidades, conocimientos que poseen y que además pueden desarrollar más, teniendo como objetivo 
consecuente que el estudiante, sobre la base de una motivación intrínseca, tome una mayor responsabilidad en su propio aprendizaje dentro y fuera de clase.

Otro fundamento de este método es el "Proyecto Zero", de la Escuela de Postgrado en Educación de la Universidad de Harvard, donde labora Howard Gardner y de donde emana directamente la Teoría de las Inteligencias Múltiples, base de este estudio, y que, en su aplicación más avanzada, se está dando con un enfoque interdisciplinario de "Enseñanza para la Comprensión"; esta se fundamenta en la aplicación del Método de Proyectos con una perspectiva interdisciplinaria (Instituto Innova, 2008). Esta técnica se profundiza en el estudio de la interesante experiencia novedosa que se está desarrollando en los Centros Modelo objeto de esta investigación (Mainieri, 2008, p. 72).

La estrategia del MBP (Instituto Buck, 2010) se enfoca a los conceptos centrales y los principios de una disciplina, involucrando a los estudiantes para la solución de problemas, así como de otras tareas significativas, permitiéndoles trabajar de manera autónoma y procurando que sean ellos los que construyan su propio aprendizaje. Para la implementación del Aprendizaje Basado en Proyectos se requieren distintos elementos:

-Un Perfil Institucional particular: El aval de la Institución en la cual se va a implementar es fundamental y es menester que cuente con amplios estándares y proyecciones sociales.

-Estrategia: Al colocar a los estudiantes ante una problemática real, se favorece un aprendizaje más vinculado con el mundo fuera de la escuela, busca relacionar el aprendizaje de los estudiantes con su realidad, lo que les permite adquirir el conocimiento de manera no fragmentada o aislada, como se da en la enseñanza tradicional, esa que es impartida por asignaturas independientes entre sí. Se caracteriza porque:

Los contenidos son significativos y relevantes para el estudiantado.

Las actividades permiten la retención y transferencia de los conocimientos, así como construir su propio conocimiento y exige a los estudiantes buscar información multivariada para resolver problemas.

Las condiciones en que se desarrollan los proyectos permiten desarrollar habilidades de colaboración e interdependencia, Favoreciendo a su vez la prevención y resolución de conflictos interpersonales, así como crear un ambiente favorable, logrando que el proyecto funcione.

$>$ El trabajo con proyectos desarrolla habilidades de trabajo productivo, aprendizaje autónomo y de mejora continua; promueve habilidades cognitivas de alto nivel, así como mejores estrategias para resolver problemas. 
-Formación profesional y el desempeño laboral de los docentes: La implementación del ABP implica formación de los docentes en dicha metodología perfilando cada vez más la cultura institucional para que esta se dirija hacia una cultura del alto rendimiento. El docente comparte el cocimiento con los estudiantes, no tiene todo el conocimiento para sí mismo, aprende junto a ellos(as), por esto es más visto como un asesor o un facilitador que como un instructor, continuamente está pendiente de la aplicación de los conocimientos en el proyecto y en el salón de clase, observando qué funcionó y qué no.

-Metodología de trabajo en equipo: El objetivo principal del Método de Proyectos es la realización de un proyecto de investigación por parte de los estudiantes organizados en grupos y por temas de interés, el BUK Institute for Education plantea cinco etapas para desarrollar el proyecto: empezar con el fin en mente, elaborar la pregunta orientadora, planear la evaluación, hacer un mapa del proyecto, administrar el proceso.

-Aspectos Evaluativos: Además de las evaluaciones tradicionales, basadas en rendimiento, proliferan evaluaciones por desempeño, tomando como base el uso del conocimiento y las habilidades por desarrollar en los proyectos y, principalmente, una exposición pública al finalizar.

-Participación del estudiantado: En esta metodología los y las estudiantes toman una mayor responsabilidad de su propio aprendizaje y aplican, en proyectos reales (resolver problemas o proponer mejoras en las comunidades en donde se desenvuelven) las habilidades y conocimientos adquiridos en el salón de clase.

Se motiva en los estudiantes el amor por el aprendizaje, un sentimiento de responsabilidad y esfuerzo y un entendimiento del rol tan importante que tienen en sus comunidades, así como de asumir la responsabilidad de su propio aprendizaje. El MBP surge como respuesta a la interrogante del momento en la que se plantea el reto de la educación para la vida, con intensión de desarrollo holístico de las diferentes inteligencias con el fin de lograr el desarrollo psicosocial del individuo.

El anterior marco teórico, que tan brevemente se reseña, resulta fundamental para la práctica educativa en los CEM estudiados y son objeto de capacitaciones y planeamiento educativo anuales.

\section{Metodología}

La investigación tuvo por objeto desarrollar un marco teórico más amplio referente a las Inteligencias Múltiples y el paradigma constructivista. Asimismo se buscaba conocer las 
conceptualizaciones teóricas y estrategias metodológicas y evaluativas que utilizan los y las docentes de primer ciclo para favorecer el desarrollo de las IM (por medio del estudio de un modelo de aplicación) y las posibilidades de aplicación en el primer ciclo del sistema educativo público (por medio del estudio de una pequeña muestra de escuelas).

Se realizó una investigación aplicada con fines exploratorios, recurriendo a una metodología cualitativa, con la aplicación y análisis de entrevistas semiestructuradas con preguntas abierta y en profundidad a docentes y a personas expertas, para lo que se construyó y validó el instrumento "Guía de entrevista" (Mainieri, 2008); esto con muestras de educadores/as de tipo teórico (Taylor y Bogdan, 1992) y observación en el campo de trabajo, además de la realización de grupos focales.

Los principios teórico metodológicos que guían esta investigación son fundamentalmente interpretativos y hermenéuticos. Se centra en lograr la comprensión de un fenómeno y sus relaciones, no en explicar ni generalizar; se sustenta en una función personal del investigador, no impersonal, y hace referencia a la construcción de un conocimiento del tema en estudio, que es lo que se busca.

Estrategia metodológica: De previo a la aprobación de la propuesta de investigación que se trata, se logró identificar entre la población de centros de educación primaria costarricenses, una única escuela que considera como parte del ideario de su misión la aplicación de la TIM, precisamente fue este hecho el que marcó el aval para la realización de la investigación, después de un implas de dos años de espera. Se trata de un centro privado que, precisamente, podría ser un modelo de aplicación para el sector público y al que denominamos Centro Modelo (CM).

Al establecer el contacto y la negociación de la entrada, se logró ubicar a una de las educadoras, informantes clave para la investigación, como asistente del proyecto, lo que resultó determinantemente exitoso, además de contar con expertas en el tema, las dos Directoras y la Psicopedagoga, aparte de un profesorado capacitado en esta línea de trabajo.

Así se hizo posible la construcción de un amplio marco teórico y práctico, "banco de materiales", documentos y datos, a la luz de lo cual se diseñó la "Guía de entrevista" (Mainieri, 2008), instrumento principal para la realización de la parte empírica y recogida de la información, además de plasmar el modelo de aplicación con sus características propias (ver Anexo). 
En otro momento y con el fin de estudiar este modelo comparativamente con las escuelas del sector público, se procedió a seleccionar tres escuelas al azar y por conveniencia, cercanas a zona de trabajo y con buena disposición a participar (3 de 6).

Inicialmente se llevaron a cabo 10 entrevistas abiertas, algunas de ellas en dos sesiones. Fueron realizadas a las 2 directoras, la Psicopedagoga y la informante clave, 4 más fueron realizadas a miembros de la Junta Directiva del CEM y recogen aspectos históricos y de desarrollo así como del modelo educativo y medio ambiente escolar; esto además de diferentes visitas de observación y las que corresponden a las 6 sesiones para filmar la experiencia de desarrollo del perfil intelectual con un grupo de niños de segundo grado del Centro Educativo Modelo (Mainieri, 2010).

Posteriormente, se llevaron a cabo un total 16 entrevistas, a profundidad, cinco corresponden a las docentes del CEM, en dos sesiones cada una y 11 se desarrollaron en las tres EP, también en dos sesiones, además de las visitas de negociación de la entrada. Este grupo de entrevista es el que se sistematiza en el análisis de resultados. Las categorizaciones seguidas durante los procedimientos analíticos permiten una organización y profundización de los datos. Su recolección y sistematización se realizó sobre la base de los emergentes fundamentales, a partir de los que se estructuraron cuatro categorías de análisis principales:

> Aspectos generales de la formación profesional y desempeño laboral de las docentes

> Conceptualización de la Teoría de las Inteligencias Múltiples

$>$ Estrategias pedagógicas y de evaluación para el desarrollo de las Inteligencias Múltiples en el aula

$>$ Posibilidades de aplicación al Sistema Educativo Público

El análisis de datos se resume en gráficos y argumentaciones comparativas entre el CEM y la muestra de EP.

Se logra además validar el modelo costarricense analizado confrontándolo con autoridades académicas del CEM en Costa Rica, mediante técnicas de grupo focal, por lo que se realizó una presentación de la descripción del modelo educativo analizado, ante las expertas de CEM con el objeto de evaluar, con mayor fundamento, las posibilidades de aplicación en el sector público ya tratadas en las entrevistas individuales efectuadas a docentes de ambos grupos, el CEM y las EP.

Con el objeto de retroalimentar la experiencia del modelo de aplicación estudiado en Costa Rica y siendo este el único que se encontró después de una larga búsqueda, se logró 
la proyección a otro país de la Región. Así fue como en una Segunda Fase, se realiza una réplica del estudio en Chiriquí-Panamá, logrando una profundización en el estudio de otro CEM, también analizado comparativamente con tres escuelas públicas de esa región (Mainieri y Carvajal, 2011). No obstante lo que aquí se presenta es la experiencia y los resultados para Costa Rica. Asimismo, se desea que los resultados obtenidos aporten bases para fortalecer la estimulación de las Inteligencias Múltiples en otros ámbitos y contextos educativos.

\section{Resultados}

\section{La teoría}

Primeramente, ha resultado invaluable la profundización teórica realizada: la Teoría de las Inteligencias Múltiples desde sus orígenes en la Genética y las Neurociencias; la Teoría de la Canalización Genética con sus procesos genéticos que acompañan el fenómeno de la adaptación biológica evolutiva; la Teoría de la Plasticidad Cerebral como la posibilidad de elevar o perder potencialidades humanas que porta el niño(a) al nacer, dadas sus particularidades físicas, neurológicas y psicológicas a la temprana edad y que se despliegan y desarrollan de acuerdo con las demandas del ambiente y sus estímulos; y la complejidad que se presenta en la definición de Inteligencia y en la determinación de su heredabilidad versus influencia ambiental.

Las teorías mediacionales, en las que median elaboraciones internas del individuo y las aplicaciones constructivistas a la Educación, el MBP y el Aprendizaje Interdisciplinario para la Comprensión, que también se tocan, resultan en un trasfondo teórico propicio a la implementación de la TIM en el currículo.

En la TIM, se parte de la premisa de que, para que los niños y niñas logren desarrollar sus múltiples capacidades intelectuales y/o consecuentes habilidades, es importante propiciar una adecuada estimulación. Las Inteligencias estudiadas son ocho: lingüística, matemática, cinestésica corporal, espacial, musical, interpersonal, intrapersonal y naturalista y la adecuada interacción de las mismas permitirá el óptimo desenvolvimiento del niño y la niña en los ámbitos social, cultural y familiar.

Por otra parte, el impacto que ha tenido la TIM alrededor del mundo y que se palpa en este estudio, en una pequeña proporción, constituye un cuestionamiento muy serio a la los modelos psicométricos de la inteligencia en su aplicación pedagógica. y predominante en los procesos de selección de estudiantes. 


\section{Las entrevistas por categorías de análisis}

\section{Aspectos generales de la formación profesional y el desempeño laboral de las} docentes: Tanto en los Centros Educativos Públicos (CEP) como en el CEM la totalidad de entrevistadas fueron mujeres; asimismo, las expertas lo fuero. Las edades de las docentes de los CEP son más disímiles en comparación con las de los CEM y en el último hay docentes más jóvenes. Esto puede observarse en el gráfico 1, donde se presentan los datos por frecuencias.

\section{Gráfico 1}

Comparativo entre los Centros Educativos Públicos y el Centro Educativo Modelo, de grados académicos, edades, conocimiento de idiomas y años de experiencia en educación, las personas entrevistadas

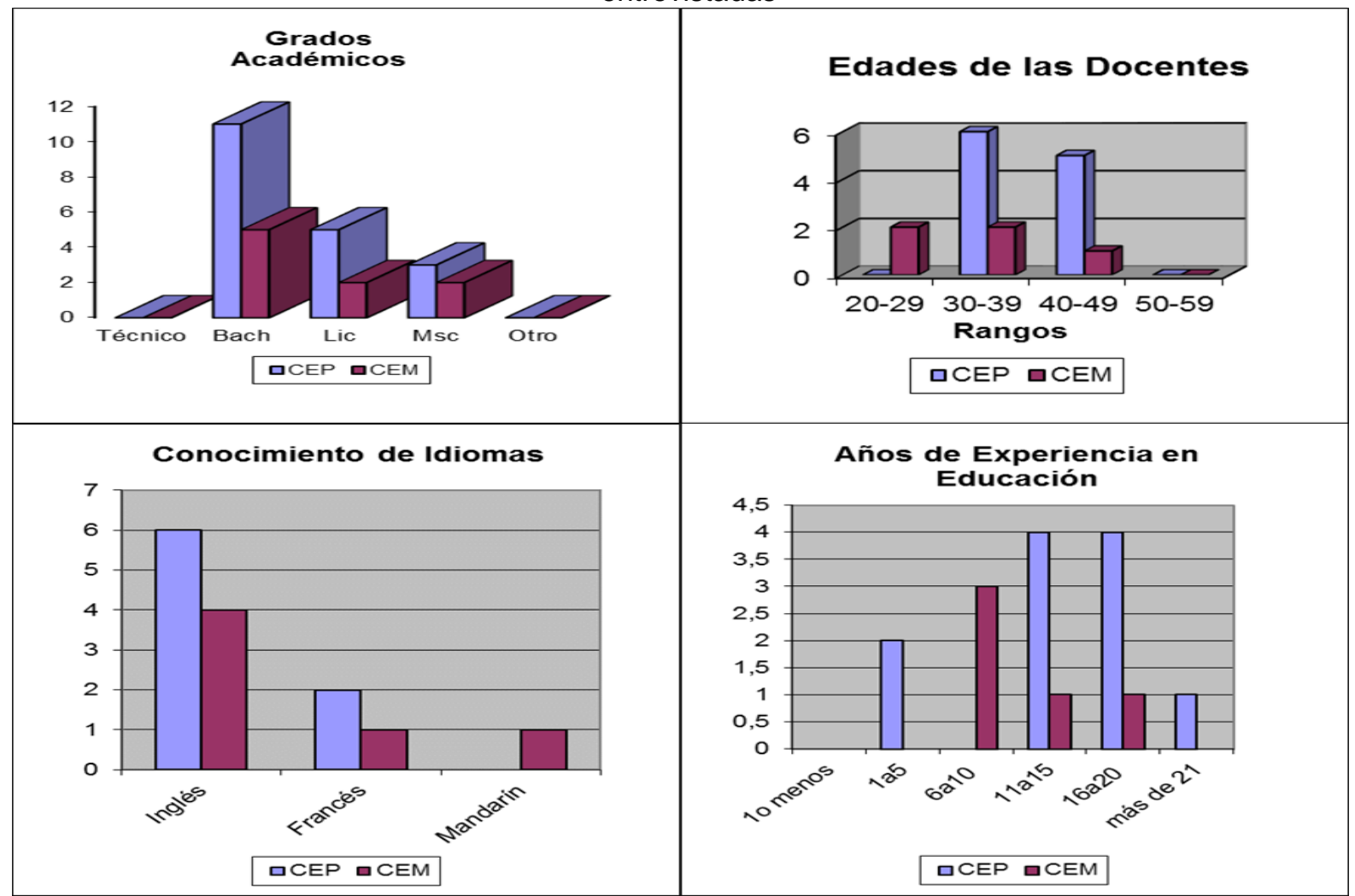

Fuente: Mainieri (2010, pp. 102, 103, 105, 108)

Asimismo puede observarse que en los CEP hay más licenciados que Masters y en el caso del CEM hay igual proporción de personas que obtuvieron éstos grados académicos. Los CEP cuentan con más años de experiencia en enseñanza, la mayoría de las docentes tienen entre 11 y 20 años, en tanto que en el CEM, la mayoría está en el rango de 6 a 10 años. El idioma inglés es el más conocido por las docentes de ambos tipos de instituciones; 
sin embargo, en los CEM hay más variedad de conocimiento de idiomas entre los que se encuentran el francés y el mandarín y se tiene un manejo más elevado del inglés.

2. Conceptualización de la Teoría: En este punto se presenta una interpretación resumida de los datos recogidos en varias secciones de la entrevista, las respuestas de las docentes contabilizadas y categorizadas que se encuentran en el "Informe de Avance: Resultados de la Primera Fase" (Mainieri, 2009).

En relación con la conceptualización de la inteligencia, las docentes de los CEP refieren en general el término capacidad; no obstante ejemplifican haciendo alusión a diversas actividades de comprensión, acción, entendimiento, poder hacer las cosas, la resolución de problemas, el aspecto cognitivo, aptitudes (cognitiva, emocional, artística); así como reacciones ante un contexto, la comunicación o el desenvolvimiento ante situaciones determinadas, posibilidad de desarrollarla por medio de la voluntad. Las docentes del CEM, en cambio, tienen mayor coincidencia en la caracterización de la misma, enfocando la esencia como factor común en la resolución de problemas en diversas áreas, aspecto retomado solamente por una de las docentes de los CEP.

Como factores que pueden retardar la inteligencia, en ambos tipos de centros educativos hacen alusión, no solo a factores individuales, sino que incluyen en sus definiciones elementos de índole social como el ambiente, la estimulación, la metodología, entre otros.

Para catalogar a un/a buen/a estudiante: los resultados son similares en ambos tipos de centros educativos. Se hace referencia al aspecto dinámico del niño o niña en el proceso de enseñanza-aprendizaje, pero también se indican factores de motivación y estimulación. En los CEP, exclusivamente, también se refiere el apoyo del hogar. Ninguna docente se centra en la consideración de las calificaciones, más bien se hace referencia, en repetidas ocasiones, al hecho de que se haga el esfuerzo por salir adelante, avanzar, llegar a la meta y se valora más la responsabilidad u otras habilidades y características, la mayoría de ellas de orden psicosocial y actitudinal, más que aptitudinal.

Las docentes de EP, en su mayoría, no estaban de acuerdo con que el plan de estudios potencializa la inteligencia, se hicieron presentes señalamientos en los que se aclaran deficiencias del mismo, entre éstos se detallan aspectos de incompatibilidad con la realidad de los y las estudiantes, de cantidad de estudiantes o de tiempo para cumplirlo. Por otra parte, todas las docentes del CEM estuvieron de acuerdo en que el plan de estudios 
potencializa la inteligencia; una de ellas aclara que dicho plan proviene del MEP y, sin embargo, bien se ajusta a la filosofía y metodología de la institución en la que labora. De esta manera, el plan se define desde el inicio pero "el profesor toma el plan de estudio para hacer su propia programación de los objetivos y contenidos e integra lo que son las inteligencias". (EP.16).

En el caso del CEM, la población estudiantil talentosa parece ser muy significativa y variada; las docentes describen con distintos ejemplos las actividades que realizan con sus estudiantes y que ellas reconocen dentro de este término. Una de las entrevistadas expresa: “... encasillan a los estudiantes que son talentosos en la lógica matemática o en áreas de lingüística y son los estudiantes inteligentes para muchos docentes, cuando se dejan de lado estos otros talentos... entonces no podemos generalizar, hay que especificar muy bien que ser talentoso no significa que, ya por eso, se tenga que decir que es inteligente en todas la áreas" (EP.14). No siendo así en los CEP, la totalidad de docentes concuerdan en que el talento es una expresión de inteligencia en su amplia gama de acuerdo con la TIM.

En lo que respecta al conocimiento de la Teoría de las Inteligencias Múltiples: todas las docentes del CEM-CR la conocen, no así las de escuelas públicas. De éstas últimas, 6 docentes algo recordaron de ella y 5 reportaron no tener conocimiento al respecto; las primeras ofrecen respuestas mucho más detalladas y amplias. Las docentes de la escuela modelo, aportaron explicaciones tanto de la teoría como desde su experiencia personal, al desarrollar planeamiento desde los distintos tipos de inteligencia.

En las escuelas públicas, ninguna de las docentes logró identificar las 8 inteligencias básicas de la TIM: solo dos pudieron mencionar 7, y otra más identificó 6 . En el caso de las docentes del CEM, 3 de las entrevistadas lograron identificar las 8 inteligencias y la otra entrevistada comentó 7; además se refieren a ellas y a su aplicabilidad ampliamente. Las primeras desconocen detalladamente sobre la teoría, mientras que las segundas, el hecho de trabajar día a día con objetivos y actividades diversas encaminadas a fortalecerlas les ha permitido conocerlas bien. En el CEM, además, han tenido capacitaciones sobre las TIM con el fin de desarrollarla en sus clases diariamente.

Pese a que las docentes de la muestra de los CEP desconocen bastante las TIM y su aplicabilidad, muestran en general una buena acogida, anuencia y entusiasmo por conocerla y un cierto reclamo, con sentido de limitación, por no recibir capacitación al respecto. 


\section{Estrategias pedagógicas y de evaluación para el desarrollo de las Inteligencias}

Múltiples en el aula: Entre las actividades para estimular las inteligencias en los estudiantes, se concede gran responsabilidad a quienes colaboran en la estimulación del estudiante. Como puede apreciarse en el gráfico a continuación, las actividades que realizan las docentes de los CEP, se caracterizaron por su diversidad y sobresalen las presentaciones de teatro; no obstante, en el CEM se detectan con mayores frecuencias una variedad mayor de estrategias, entre las que destacan: visualización de imágenes, música emotiva al tema de estudio, pensamiento científico, rimas y canciones, trabajo en parejas o grupos, publicaciones de trabajos de los estudiantes, conexiones personales al tema de estudio, elección de la distribución del tiempo, juegos de mesa, grabaciones de audio, conceptos musicales y charadas. Así se observa que las estrategias de enseñanza: contar un cuento, clasificaciones y categorizaciones, son empleadas en forma muy generalizada.

\section{Gráfico 2}

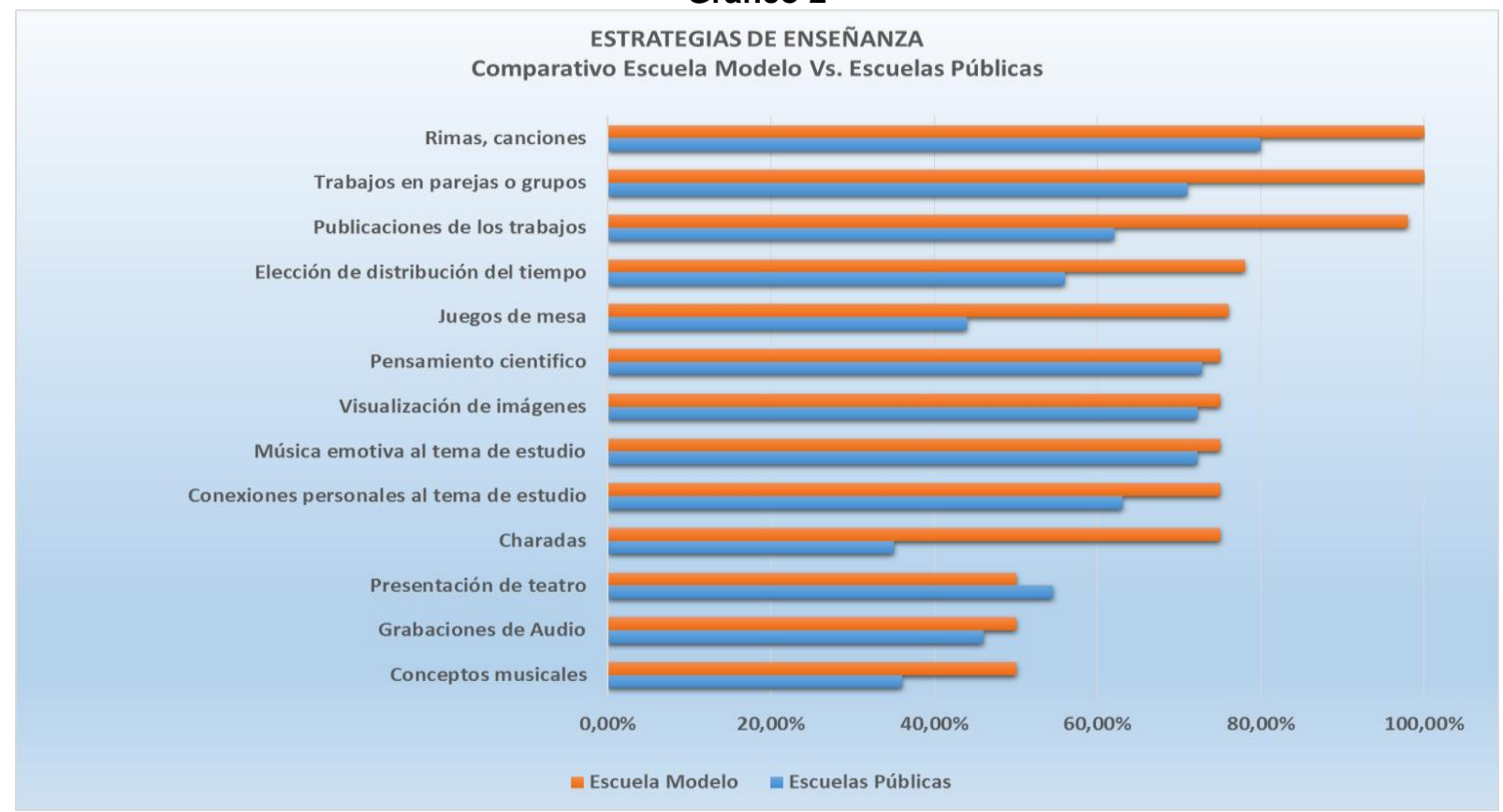

Fuente: Mainieri (2010, pp. 151-154)

Aparte de esto, en el CEM, la experiencia por excelencia consiste en el desarrollo del propio perfil de inteligencia, realizada por los estudiantes mismos y su seguimiento cada año; además de la retroalimentación que se efectúa con los padres y madres de familia a partir de él, durante todo el proceso educativo y por temas de estudio. Esta experiencia innovadora, se constituye en una perspectiva totalmente distinta del propósito educativo, 
que le da un sentido distinto con la consecuente motivación para el o la estudiante y en un vínculo estratégico entre el niño o la niña, su papá y/o mamá y el o la docente.

La otra estrategia fundamental la constituye el Método Basado en Proyectos, el que se plantea como gestor del desarrollo de las múltiples inteligencias y se observa su puesta en práctica en los centros educativos, considerados modelos de aplicación de la TIM al currículo, estudiados por la autora, el de CR y el de David, se realizan experiencias sumamente interesantes y diferentes, que se complementan en forma ideal en la estrategia pedagógica.

Los espacios del aula se reorganizan para el trabajo en grupos, los(as) docentes desarrollan unidades temáticas trabajando en equipos interdisciplinarios que se integran según lo requieran los proyectos a desarrollar y se constituyen en verdaderos guías en la administración de los proyectos, además de facilitadores del aprendizaje. La evaluación se realiza sobre los productos de los proyectos que se dan en construcciones, presentaciones y exhibiciones de resultados.

Las últimas aplicaciones del MBP abogan por una "metodología interdisciplinaria para la comprensión", de la que tratan los seminarios de "Educación para la Comprensión" de la Escuela de Harvard que se están proyectando en muchos países e inclusive en CR y que este mismo CEM ha seguido de cerca.

Las educadoras de las EP parecen, en los mejores casos, planear actividades propias, casi intuitivamente y en forma improvisada, utilizando en muchos casos recursos personales, lo que muestra su alto grado de compromiso, vocación y capacidad, pero un pobre fundamento teórico en relación con los ideales de la educación costarricense, que se dice ser constructivista, según lo manifiestan.

En cuanto a si las estrategias son más aplicables a unas materias que a otras: las argumentaciones evidencian grandes dudas, inseguridad y desconocimiento, aún más, poco dominio de la práctica profesional que entonces ¿se está dando intuitivamente? ¿qué tan conveniente resulta eso?

La estrategia de evaluación que es empleada en forma generalizada es la observación. Según se observa en el gráfico, el CEM destaca significativamente (más del $40 \%$ ) en el uso de estrategias como son: el portafolio, pruebas utilizadas informalmente. En las EP sobresale el empleo de estrategias como: registros anecdóticos, organización de las actividades por realizar en un calendario. Las otras técnicas son utilizadas igualmente por ambos grupos sin encontrarse diferencias importantes. 


\section{Gráfico 3}

Estrategias evaluativa, comparativo Escuela Modelo vs. Escuelas Públicas.

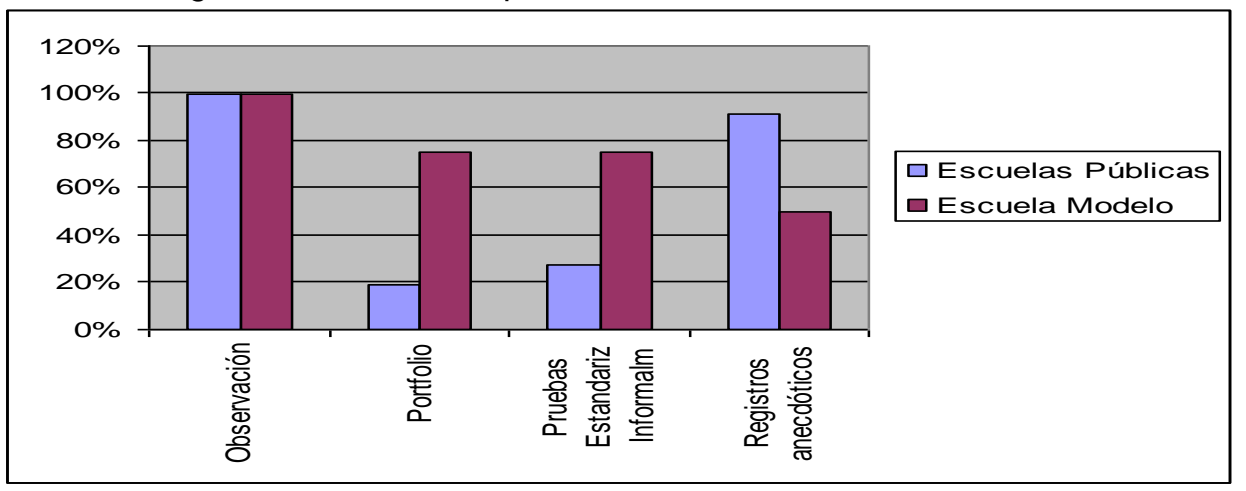

Fuente: Mainieri (2010, p. 161)

El perfil del buen educador del CEM se acerca al ideal, reflejando gran fundamento teórico, humanismo y profesionalismo, al igual que el del CEP; no obstante, en las últimas, sus definiciones ponen en evidencia retos distintos que deben sobrellevar estas docentes, tales como: realidades contextuales (problemas económicos, familiares y/o sociales), escasez de recursos materiales, grupos estudiantes muy numerosos, donde se hace presente la necesidad de lidiar con distintas condiciones del alumnado del sistema educativo público. Por tanto, ponen especial atención en lo que es el proceso de enseñanza, pero también muestran una gran apertura para aprender de la experiencia.

4- Posibilidades de aplicación al Sistema Educativo Público: Al final de las entrevistas se analizan aspectos de fácil, mediana y compleja aplicación, recopilados en un cuadro sinóptico. Las docentes de los CEM muestran una apreciación más positiva que las de los CEP, quienes reportan predominantemente elementos de compleja aplicación. Consideran que se requieren recursos, capacitaciones y docentes con ciertas características, que conlleven a cambios sustanciales en la educación. La dificultad que se señala con mayor fundamento es la gran cantidad de estudiantes por grupo con diversidad de problemáticas, el requerimiento de recursos materiales, tecnológicos e infraestructura, la voluntad política y la anuencia de los padres de familia.

Si bien, las educadoras del CEM refieren esas limitaciones, también concuerdan en que sí se podría aplicar en lo público, afirmando que no se requiere de material extraordinario, lo que sí se requiere es de creatividad y deseos de favorecer el proceso de aprendizaje. Esto se sostuvo en la sesión de grupo focal en la que se retomó este análisis. 


\section{Conclusiones}

En cuanto a la profundización teórica, el estudio brinda una amplia perspectiva en la que se comprende la ubicación de la TIM en el marco del constructivismo y su conexión con las Neurociencias, así como las posibilidades y grandes ventajas de un enfoque educativo basado en su aplicación. Se refieren las bases teórico-prácticas de su implementación con la presentación de un modelo como ejemplo, el CEM, y la evidencia de sus aportes a la educación que se observa en la relación comparativa con la muestra de escuelas públicas.

Los resultados resultan relevantes para la actualización de los Sistemas Educativos y proyecciones a todos sus niveles, esto con los requerimientos de capacitación docente, flexibilización organizacional y financiamiento, entre otros aspectos a profundizar. La exploración realizada abre grandes interrogantes y, a su vez, sirve de base para profundizar en distintos aspectos y tiene grandes implicaciones para la educación en todo sentido.

\section{Referencias}

Alvarez, Francisco. (2001). Estimulación Temprana: Una puerta hacia el futuro. Quinta edición. Argentina: Alfaomega.

Antunes, Celso. (2002). Estimular las Inteligencias Múltiples Qué son Cómo se manifiestan Como funcionan. Segunda edición. Madrid: Nancea S.A.

Espinosa, Manuel de Juan. (1997). Geografía de la Inteligencia Humana. Las aptitudes cognitivas. Madrid: Pirámide.

Gardner, Howard. (2001). Inteligencias Reformulada: Las IM en el siglo XXI. Buenos Aires: Ed. Paidós Iberoamérica.

Gardner, Howard. (1994). Estructuras de la mente: La teoría las Inteligencias Múltiples. Mexico: Fondo de Cultura Económica.

Gardner, Howard. (1995). Inteligencias Múltiples. La teoría en la práctica. Barcelona: Paidós.

Gardner, Howard; Feldman, David y Krechevsky, Mara. (2000). El Proyecto Spectrum (Tomo I). Madrid: Morata.

Gardner, Howard; Feldman, David y Krechevsky, Mara. (2001). El Proyecto Spectrum (Tomo II). Madrid: Morata.

Gardner, Howard; Feldman, David y Krechevsky, Mara. (2001). El Proyecto Spectrum (Tomo III). Madrid: Morata. 
Gardner, Howard, Kornhaber, Mindy y Wake, Warren. (2000). Inteligencias Múltiples Perspectivas. Buenos Aires: Aique grupo editor S.A.

Gimeno, José y Pérez, Ángel. (1996). Comprender y transformar la Enseñanza. Madrid: Morata.

Goleman, Daniel. (2004). La inteligencia Emocional. Barcelona: Ediciones B, S.A.

Instituto Buck para la Educación. (2010). Manual para el Aprendizaje Basado en Proyectos (Traducción al español Hogg, Silvian). San José - Costa Rica: Fundación Omar Dengo.

Instituto Innova. (2008). VIII Curso Internacional Enseñanza para la Comprensión: Educación Interdisciplinaria para el mundo contemporáneo. San José, Costa Rica: FOD.

Kilpatrick, Thomas. (1918). The Project Method. Teachers College Record, 19, 319-334.

Kolb, David, Rubin, Irwin y Mclntyre, James. (1974). Psicología de las Organizaciones: problemas contemporáneos. Prentice-Hall: Hispanoamerica S.A.

Lupiañez, Juan. (2009). Orientación espacial de la atención mediante conceptos temporales. Actas de la RECA 6. Barcelona, España: s.n.

Mainieri, Aida (2008). II Informe de Avance (Proyecto Inv. N D-Inves/2007-062). San José: UNED, Sistema de Estudios de Posgrado, Vicerrectoría de Investigación.

Mainieri, Aida (2010). Informe de Avance: Resultados de la I Fase (Proyecto Inv. N DInves/2007-062). San José: UNED, SEP, Vicerrectoría de Investigación.

Mainieri, Aida y Carvajal, Doris. (2011). Informe II Fase (Proyecto Inv. N D-Inves/2007-062). San José: UNED, SEP, Vicerrectoría de Investigación.

Nery, Rodolfo. (2009). Ciencias aplicadas al Ajedrez. Recuperado de http://ajedrezydemocracia.blogspot.com/2009/01/curso-de-ajedrez-leccin-2-psicologay.html

Nicholson, Nelson. (1998). Developing Students Multiples Intelligences. Scholastic Profesional Books. (Traducido por Salvador, Nuria). New York.

Núñez, Fernando. (1981). Canalización Genética. Valencia: Univers. Politécnica de Valencia.

Osorio, Maricela y Oblitas, Luis. (1978). Psicología de la Salud Infantil. Bogotá: Julio César Salamanca Editor.

Piaget, Jean. (1975). Psicología y Epistemología. Barcelona: Ariel.

Pérez, Rafael; Alfaro, Abraham; Arauz, Sandra; Avendaño, Mario y Rojas, Gladys. (2000). Hacia una práctica Pedagógica Constructivista. San José: MEP.

Shatz, Carla. (1992). El Cerebro Humano: Desarrollo, Actividad Cerebral y Actividad Mental Ecuador: Ministerio de Educación. 
Sternberg, Robert y Powell J. (1989). Inteligencia Humana IV. Evolución y desarrollo de la Inteligencia. Barcelona: Piados.

UNESCO. (1993). John Dewey, Perspectivas: Rev. Trimestral de Educación Comparada, 23(1-2), 289-305.

Weinberg, Richard. (1989). Intelligence and IQ. American Psychologist, 44,(2), 98-104. 


\section{Anexo: Instrumento básico utilizado}

\section{UNIVERSIDAD NACIONAL DE EDUCACIÓN A DISTANCIA INVESTIGACION / PROGRAMA DE MAESTRÍA EN PSICOPEDAGOGÍA}

\section{GUÍA DE ENTREVISTA DIRIGIDA A DOCENTES DE PRIMER CICLO}

Fecha: Hora: Entrevista \#

Entrevistadora:

El presente instrumento ha sido elaborado con el propósito de obtener información sobre el modelo educativo que se implementa en el estímulo de las Inteligencias Múltiples en los estudiantes de Primer Ciclo de la Educación General Básica.

Contando con la autorización de la Dirección Académica de la Institución para la cual Ud. labora, se le solicita su participación en una entrevista abierta en la que se pretende lograr su interés y a la que usted puede negarse si así lo desea.

La información es totalmente confidencial; los resultados podrían aparecer en una publicación científica o ser divulgados en forma anónima, empleando únicamente el número de la entrevista, lo que no implica ningún riesgo ni beneficio para usted y no tiene repercusión legal alguna. Sin embargo, su colaboración es de máxima importancia y usted estará contribuyendo con los objetivos que son de interés tanto académico como popular.

Si tiene alguna pregunta o duda puede expresarla con toda confianza ahora o en el transcurso de la entrevista. Se le invita a comunicar o enviar cualquier información adicional que considere importante en cualquier momento.

\section{Parte. Aspectos generales de la formación profesional y el desempeño laboral de los docentes.}

1. Edad

$(\quad) 20-29$

( $\quad 30-39$

( $40-49$

( $50-59$

2. Sexo

( ) Femenino

3. Grado académico y título (s) universitario (s)

$\begin{array}{lll}(\quad) \text { Técnico } & \text { () Bachillerato } \\ (\quad) \text { Licenciatura } & \text { ( ) Maestría } \\ (\quad) \text { Otro, ¿cuál? }\end{array}$

4. Años de experiencia laboral en Educación.
( ) Menos de 1 año
( ) 1 a 5 años
( ) 6 a 10 años

$\begin{array}{ll}(\quad) & 11 \text { a } 15 \text { años } \\ ( & 16 \text { a } 20 \text { años } \\ & \text { ) } 21 \text { o más años }\end{array}$

5. Años de experiencia laboral en una institución educativa que trabaje favoreciendo las Inteligencias Múltiples.

( ) Menos de 1 año

( ) 1 a 5 años

( ) 6 a 10 años

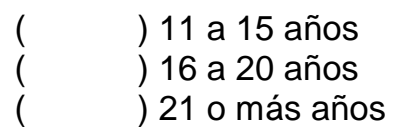


6. Grado en que imparte lecciones

$(\quad)$ Primero
$(\quad)$ Segundo
( ) Tercero

7. Asignatura(s) que imparte

$\begin{array}{ll}( & \text { ) Ciencias } \\ ( & \text { ) Estudios Sociales } \\ ( & \text { ) Matemáticas } \\ ( & \text { ) Español } \\ ( & \text { ) Inglés } \\ ( & \text { ) Otra, ¿cuál? }\end{array}$

8. Idiomas y su dominio general, además del Español.

\begin{tabular}{|c|c|c|c|}
\hline ) Inglés & Básico & Intermedio & Avanzado \\
\hline ) Francés & Básico & Intermedio & Avanzado \\
\hline $\begin{array}{l}\text { Mandarín } \\
\text { Otro, ¿cuál? }\end{array}$ & Básico & Intermedio & Avanzado \\
\hline
\end{tabular}

II Parte. Conceptualización de la teoría de las Inteligencias Múltiples.

8. ¿Qué entiende por inteligencia?

9. ¿Cuáles son los factores que pueden retardar una inteligencia?

10. ¿Qué actividades realiza para estimular las inteligencias en sus estudiantes?

11. ¿Cómo define usted a un buen estudiante? Cite características (papel que juega en el proceso de enseñanza aprendizaje)

12. ¿Considera usted que el plan de estudio del grado en el que usted imparte lecciones, potencializa la inteligencia en los estudiantes?

13. ¿Ha descubierto o notado algún "talento" en sus estudiantes? Si su respuesta es Sí, pase a la siguiente pregunta y si es No, pase a la pregunta 15.

14. ¿Considera usted que dicho talento puede ser una expresión de inteligencia? ¿Por qué?

15. ¿Conoce usted la teoría de las inteligencias múltiples propuesta por Howard Gardner?

16. ¿Cuál es la principal finalidad de la teoría de las inteligencias múltiples propuesta por Howard Gardner?

17. ¿Qué plantea la teoría de las Inteligencias Múltiples?

18. ¿Conoce usted cuáles son las ocho inteligencias múltiples de las que habla Howard Gardner? Brevemente explique cada una de ellas.

19. ¿Qué tipo de formación ha tenido usted con respecto al tema de las inteligencias múltiples?

20. ¿Cuándo fue la última vez que recibió un curso o charla sobre "la teoría de las inteligencias múltiples aplicada a la Educación?

\section{Parte. Metodología, técnicas o estrategias y evaluación en el desarrollo de las Inteligencias Múltiples en el aula.}

21. ¿Cuál es el proceso de aplicación de la teoría de las inteligencias múltiples en el aula?

22. ¿Cómo se pueden estimular las inteligencias múltiples en el aula? 
23. ¿Conoce usted algún método (s) pedagógico (s) aplicable a la enseñanza de los contenidos en las diferentes materias escolares? ¿Cuál sería? ¿Cómo lo aplica?

24. ¿Considera que el método (s) pedagógico (s) es (son) más aplicable (s) a unas materias más que a otras? Especifique.

25. ¿Qué tipo de técnicas o estrategias y recursos utiliza para estimular las diferentes inteligencias múltiples? Cite algunos ejemplos.

26. Marque con una $X$ la (s) estrategia (s) de aprendizaje que comúnmente emplea en sus lecciones. Mencione a cuál (es) de la (s) inteligencia (s) favorece (en) las actividades marcadas y por qué la (s) aplica...

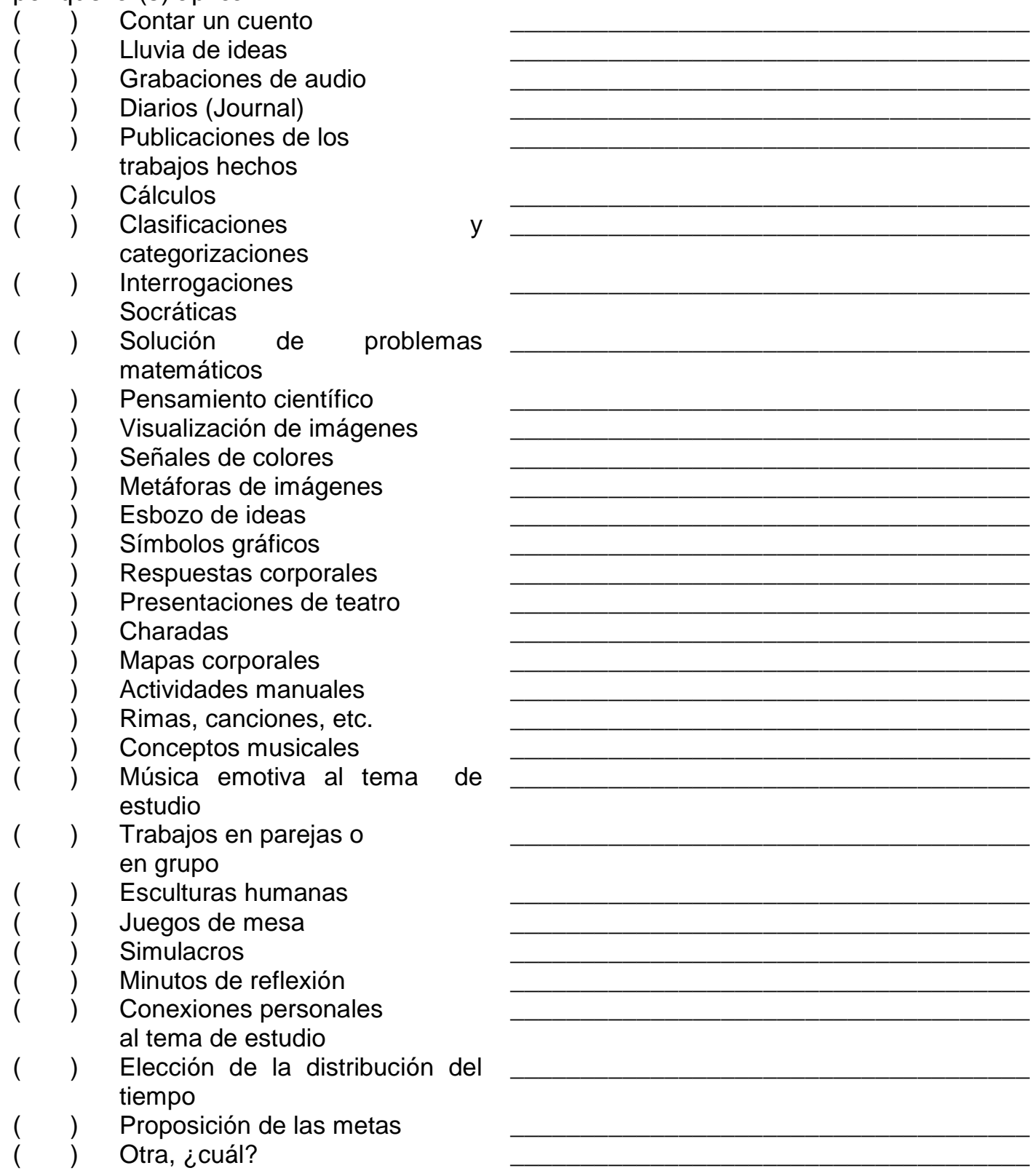

27. ¿Son los contenidos de los programas de estudio evaluados de manera diferente al implementar las inteligencias múltiples en el proceso de enseñanza aprendizaje? 
28. Marque con una $X$ las estrategias de evaluación que emplea usted para valorar el proceso de aprendizaje de sus estudiantes y explique por qué. Agregue alguna (s) si es necesario.
( ) Portfolio
( ) Fotografías
( ) Observación
( ) Sociogramas
( ) Listas de cotejo
( ) Pruebas informales
( ) Registros anecdóticos
( ) Diarios de los estudiantes
( ) Grabaciones en audio o video
( ) Entrevistas con los estudiantes
( ) Registro de las hojas de trabajos
( ) Uso de pruebas estandarizadas informalmente
( Cuadros que reflejen el avance de los estudiantes
( ) Organización de las actividades por realizar en un calendario
( ) Espejos de clase con la distribución de las actividades del día

\section{Parte. Posibles aplicaciones al Sistema Educativo Público.}

29. ¿Considera que la T.I.M. es aplicable al sistema educativo público? Enumere los aspectos de fácil, mediana y compleja aplicación. ¿Por qué?

\begin{tabular}{|c|c|c|}
\hline & Mediana & Compleja \\
\hline & & \\
\hline & & \\
\hline & & \\
\hline & & \\
\hline & & \\
\hline & & \\
\hline & & \\
\hline
\end{tabular}

Justifique sus respuestas para cada una de estas categorías.

30. ¿Cuál sería el perfil de un buen Educador en este sentido?

31. ¿Qué le pareció la entrevista? ¿Qué más debería preguntarse? ¿Qué información le parece importante agregar sobre este tema? Dado este tema, ¿a quién considera usted que se debería entrevistar?

OBSERVACIONES: 